\title{
POSITIVE AND NEGATIVE PHOTOELECTRICAL PROP- ERTIES OF MOLYBDENITE AND SEVERAL OTHER SUBSTANCES
}

\author{
By W. W. Coblentz
}

CONTENTS

I. Introduction

I. Historical data on photonegative sensitivity ............. 596

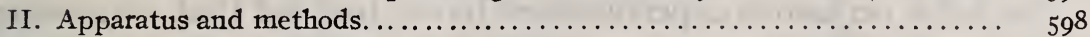

III. Photoelectric reactions in stibnite. . . . . . . . . . . . . . . . . 600

I. Effect of temperature...................... 60 I

2. Effect of direction of current through the crystal............ 602

3. A spectrophotonegative reaction in stibnite.............. 603

IV. Photoelectric reactions in silver sulphide. . . . . . . . . . . . . 603

I. Response-time observations....................... 604

2. Effect of direction of current...................... 605

3. Effect of temperature.......................... 605

V. Photoelectric reactions in molybdenite.................... 607

I. General observations............................. 607

(a) Unipolar conduction $\ldots \ldots \ldots \ldots \ldots \ldots \ldots \ldots \ldots \ldots \ldots \ldots . \ldots \ldots \ldots$

(b) Photoelectric sensitivity of different parts of the crystal... 608

2. Isochromatic observations........................ 609

(a) Photoelectric response-time curves for different voltages

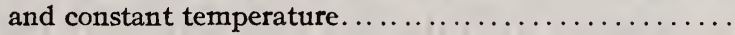

(b) Variation of photoelectric sensitivity with voltage at constant temperature.................... 6 Ir

(c) Overshooting-voltage constant, temperature variable.... $6 \mathrm{r}_{3}$

3. Spectral observations. ............................ 6r6

(a) Variation of spectrophotoelectric sensitivity with voltage and direction of current. .................... 616

(b) Variation of photoelectric reaction with intensity of the

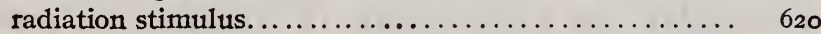

4. Observations on a photonegative spot................ 622

(a) Isochromatics - effect of voltage and direction of current. . 622

(b) Isothermals - effect of direction of current........... 623

5. Observations on a photonegative-photopositive spot......... 625

6 . Concerning reaction time.............................. 626

7. Discussion of data on molybdenite................. 627

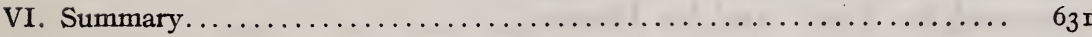

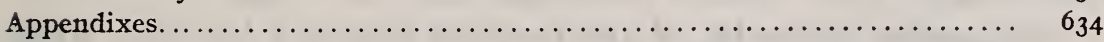

APPENDIX I. Further data on the spectrophotoelectric-frequency relation

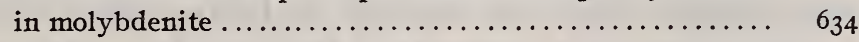

APPENDIX 2. Some general characteristics of spectrophotoelectric conduc-

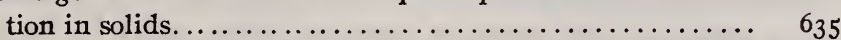

APPENDIx 3. Thermal radiophonic signaling devices.............. $6_{3} 6$ 


\section{INTRODUCTION}

A substance which changes in electrical conductivity when exposed to light is said to be photoelectrically sensitive. It is found that most of these photosensitive substances have a low electric conductivity, when they are kept in the dark; and, hence, when connected in series with a galvanometer and an electric battery, a small "dark" current flows through the circuit. On exposure to light, the photsensitive substance usually increases greatly in electrical conductivity. This type of reaction or response is said to be "photopositive." The most commonly known substance showing this type of reaction is selenium.

On a few occasions experimenters have observed that, on closing the circuit, the galvanometer deflection was less when the substance was exposed to light than when it was kept in the dark. Or, on a closed circuit, the galvanometer deflection moved in a negative direction from its zero position, when the substance was exposed to light, thus indicating an apparent rise in resistance which was higher than that which obtains in the dark. This type of response is said to be "photonegative."

The object of the present paper is to place on record some recent observations on photosensitivity and in particular the photonegative phenomena observed in a certain sample of molybdenite.

The importance of having a record of such unusual phenomena will be apparent from the fact that heretofore the mention of such data has been merely incidental.

These isolated bits of information have been assembled in the present paper in order to show their relation to the newly observed data. The whole compilation is but little more than a starting point in a new line of research that may yield information which will explain the phenomenon of photoelectric sensitivity.

\section{HISTORICAL DATA ON PHOTONEGATIVE SENSITIVITY}

A photonegative action in certain samples of selenium when exposed to the total radiation from an incandescent lamp was observed by Ries ${ }^{1}$ and by Brown. ${ }^{2}$

The general character of the reaction observed by Ries, when the selenium cell was exposed to light, was a rapid increase in conductivity (galvanometer deflection) to a maximum, followed by a gradual decrease in conductivity, which, in some cases, was 
even less than that of the unilluminated cell. On shutting off the light, there was a further rapid decrease in conductivity to a minimum, after which the conductivity of the cell gradually increased to the normal value which obtained in the dark.

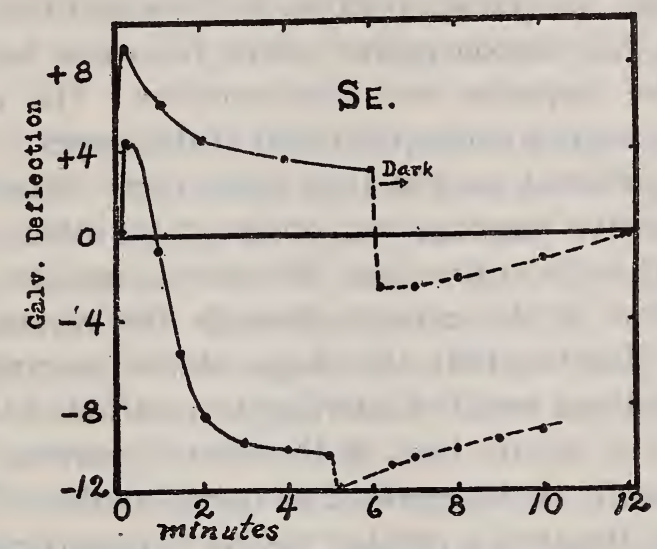

FIG. I.-Response-time curve of selenium (Ries)

A typical example observed by Ries is illustrated in Fig. I, in which the continuous line represents the photoelectric response of selenium on exposure to a weak light, while the dotted part of the curve represents the recovery after shutting off the light stimulus. The upper curve represents the behavior of the cell when new; and the lower curve the behavior after a lapse of six days. Data on temperature and applied voltage were not given.

As noted subsequently in the main part of this paper, these curves are similar to those observed on molybdenite, under certain conditions as to temperature and applied voltage.

Ries explained this phenomenon as being caused by the absorption of moisture, which produced polarization. However, he points out (on p. 575, loc. cit.) that polarization alone does not fully explain the phenomenon. Ries's experiments do not appear sufficiently extensive to demonstrate that moisture produces the photonegative reaction.

Brown (loc. cit., p. 20) obtained data in agreement with Ries, but he considered the phenomenon the result of the presence of a third or modified type of the photopositive variety of selenium.

As ordinarily constructed, the selenium cell is not well adapted for studying the effect of voltage, etc.; but molybdenite is peculiarly well adapted to observe the effects of transmission, reflection, voltage, etc., upon photoelectric reaction. 
Elliot ${ }^{3}$ observed a spectral photonegative response in certain samples of stibnite. In his preliminary test, using the total radiation from an incandescent lamp, the cells appeared to be normal in their electric response. However, on exposure to monochromatic radiation, for certain regions of the spectrum the response of these cells was photonegative, while for wave lengths greater than $0.66 \mu$ the response was photopositive. His experimental data are discussed in a subsequent part of this paper. (See Fig. 2.)

It will be sufficient to add that while these data show that a true photonegative response was observed by others, the present paper shows it to be a function of both the applied voltage and of the direction of the current through the crystal. Pfund's 4 observations, showing that the shape of the spectral sensitivity curve is affected as a result of altering the position of the electrodes and hence of the stream lines of the electric current through the crystal, can hardly be interpreted as being similar to the reversal of the current through a crystal having symmetrically attached electrodes.

The present paper represents an extensive investigation of some preliminary observations on a photonegative reaction in molybdenite, made with the assistance of $\mathrm{H}$. Kahler. ${ }^{5}$ This preliminary work was interrupted as the result of Mr. Kahler's undertaking other activities; but sufficient data were obtained at the time to demonstrate the great effect of the applied voltage upon the photoelectric response. After an interruption of six months, it has remained for the writer to localize the photonegative spot, study the effect of direction of the current, the effect of temperature and of numerous other variables which enter the problem. Suffice it to say that the various phenomena recorded have been observed repeatedly, both qualitatively and quantitatively, so that there can be no question of their reality. As for their explanation, that is quite a different matter which will not be attempted in this paper.

\section{APPARATUS AND METHODS}

The arrangement of the apparatus and the methods of operation were practically the same as used in the previous investigations of molybdenite. ${ }^{6}$ The temperatures were measured by means of a thermocouple, as previously described.

\footnotetext{
${ }^{3}$ Elliot, Phys. Rev. (2), 5, p. 62; 1915 .

${ }^{4}$ Pfund, Phys. Rev. (2), 7, p. 289; 1916.

${ }^{6}$ Coblentz and Kahler, Jour. Wash. Acad. Sci., 9, p. 537; 1919.

${ }^{\circ}$ B. S. Scientific Papers, 15, p. I20, Fig. 2; 1919.
} 
Instead of a fluorite prism, a quartz prism was employed with the view of determining the effect of a larger dispersion upon the complex band of photoelectric sensitivity which extends from 0.7 to $I \mu$. The dispersion of quartz in this region of the spectrum is about twice that of fluorite. Nevertheless, the maxima of these bands are not much more sharply defined than previously observed.

By using the quartz prism, which was of large size, there was a gain in intensity which enabled investigations through the visible and well into the violet part of the spectrum.

The source of radiation was a 500-watt, gas-filled tungsten lamp, mounted in front of the spectrometer slit. Repeated calibrations of the lamp, made at various times during this investigation, showed that any aging it may have undergone did not affect the equal energy values used.

The total intensity of the radiation stimulus for the slit image Io by $0.5 \mathrm{~mm}$, was about $\mathrm{I} \times 1 \mathrm{IO}^{-6}$ watt. For the visible spectrum extending into the violet the intensity was much less than this value. However, this specification has but little meaning in the greater part of the present investigation because of the fact that the photoelectric sensitivity is localized in a small spot of the crystal, and hence the energy actually utilized in the reaction may be only one one-hundredth of this value.

For proper interpretation of the observations it is important to remember that the photosensitive substance was connected in series with a high resistance (50 000 to 100000 ohms), a dry battery, and a d'Arsonval galvanometer. The galvanometer deflection was read by noting the position of the image of a Nernst glower upon a ground-glass scale. The effect of the dark current, which was small, was overcome by torsion of the galvanometer suspension. An increase in current through the circuit, such as usually resulted from exposure of the crystal to radiation, caused the spot of light to travel to the right. Similarly, a decrease in the current (the photonegative response) caused the spot of light to move to the left of the zero (equilibrium) position. These are the positive and negative galvanometer deflections shown in the following illustrations.

In order to simplify the exposition of the data in these illustrations, the continuous part of the curve represents the movement of the galvanometer needle-that is, the photoelectric response or reaction-on exposure of the photosensitive substance to the radiation stimulus, and the dotted part of the curve 
represents the reaction or recovery of the substance after exposure. This performance was brought about by opening and, after a given time, closing a shutter which was placed between the spectrometer slit and the lamp.

In connection with these high resistances, the galvanometer was undamped, giving a ballistic throw in two to three seconds. Repeated tests showed that, although the undamped swing of the galvanometer needle may have affected the magnitude of some of the observations, the unusual reactions, recorded here as "throws" or "kicks," appear to result from changes in the crystal. For example, it was not found possible to produce the small reactions illustrated in this paper by suddenly changing the current through the circuit, either by changing the voltage, or by varying the external resistance, so as to produce a galvanometer deflection equal to that produced by the photoelectric action.

Many of these minerals have strong unipolar conduction, the resistance ${ }^{7}$ differing by as much as 50 per cent on reversal of the current through the crystal. This is easily observed by merely reversing the current through the galvanometer and crystal. In the present paper, particularly in the illustrations, the symbol $C$. D. (current direct) is used to indicate that the current passed (lengthwise) through the crystal in the direction in which the conductivity was the greatest. Conversely, the symbol $C . R$. indicates the current reversed, in which case the electrical conductivity was the least.

\section{PHOTOELECTRIC REACTIONS IN STIBNITE}

The original crystal of stibnite, $\mathrm{Sb}_{2} \mathrm{~S}_{3}$, from Japan, was about I 5 to $20 \mathrm{~cm}$ in length and 3 to $5 \mathrm{~cm}$ in diameter. Samples of this crystal were examined by Elliot. ${ }^{8}$ However, for continuity and completeness of this Bureau's work on this subject, it was of interest to obtain the data herewith presented.

The material examined was in the form of cleavage sections. The size of sample No. I was 7 by 2.2 by $0.2 \mathrm{~mm}$; of No. 2, Io by 2.5 by $0.4 \mathrm{~mm}$; and of No. 3, 4 by 5 by $0.6 \mathrm{~mm}$. The electrodes were fine (No. 36$)$ copper wire wound in notches cut near the ends of the samples. The ends of the crystal and the wires were then covered with solder, leaving lengths, respectively, of 7,10 , and $4 \mathrm{~mm}$ of the above mentioned crystals to be exposed to radiation. 
As observed by others, the specific (dark) resistance decreases with the applied voltage. Furthermore, on constant voltage the resistance decreases with time. However in the course of an hour, on constant voltage, the conductivity, especially of cell No. I which was quite thin, became quite constant. At room temperature the maximum deflection on exposure to radiation was attained in 5 to 30 seconds. Recovery after exposure was quite complete within $I$ to 2 minutes. At low temperatures, in the region of greatest photoelectric reaction, it required 40 to 60 seconds to obtain a practically complete reaction. Elliot found great difficulty in this respect, mentioning intervals of 35 minutes between readings. This difference probably arose from the fact that his type of construction of the cell was entirely different from the present. In the present work, the photoelectric reaction seemed to attain equilibrium the quickest in the thinnest samples.

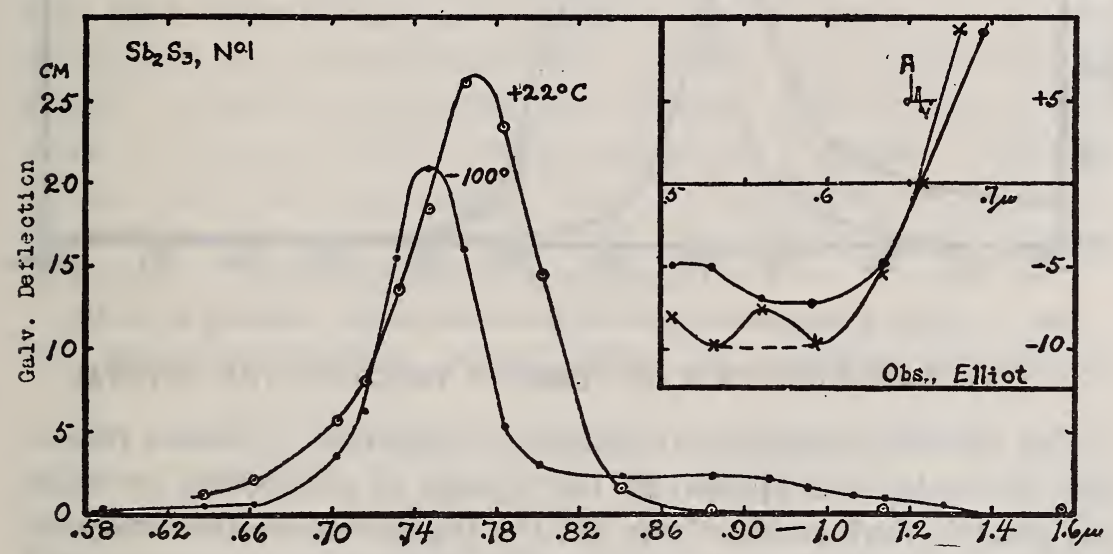

FIG. 2.-Spectrophotoelectric sensitivity of stibnite

The samples had quite a high resistance and, hence, could be joined directly through the battery and d'Arsonval galvanometer.

\section{EFFECT OF TEMPERATURE}

Observations on the change in the spectrophotoelectric sensitivity of sample No. I with temperature are illustrated in Fig. 2. The applied potential was kept constant at about 60 volts. For $-100^{\circ} \mathrm{C}$, the deflections were twice the value indicated, viz, $40 \mathrm{~cm}$ at the maximum.

Data on sample No. 2 at $20^{\circ} \mathrm{C}$ (6o volts) and $-8 \mathrm{I}^{\circ} \mathrm{C}(200$ volts) are illustrated by the solid line curves in Fig. 3 .

Data on sample No. 3 at $2 \mathrm{I}^{\circ} \mathrm{C}$ and 22 volts are illustrated by the dotted curve, Fig. 3 . 
The results of this examination show that with decrease in temperature the maximum of the response curve shifts toward the short wave lengths, which is in agreement with previous observations.

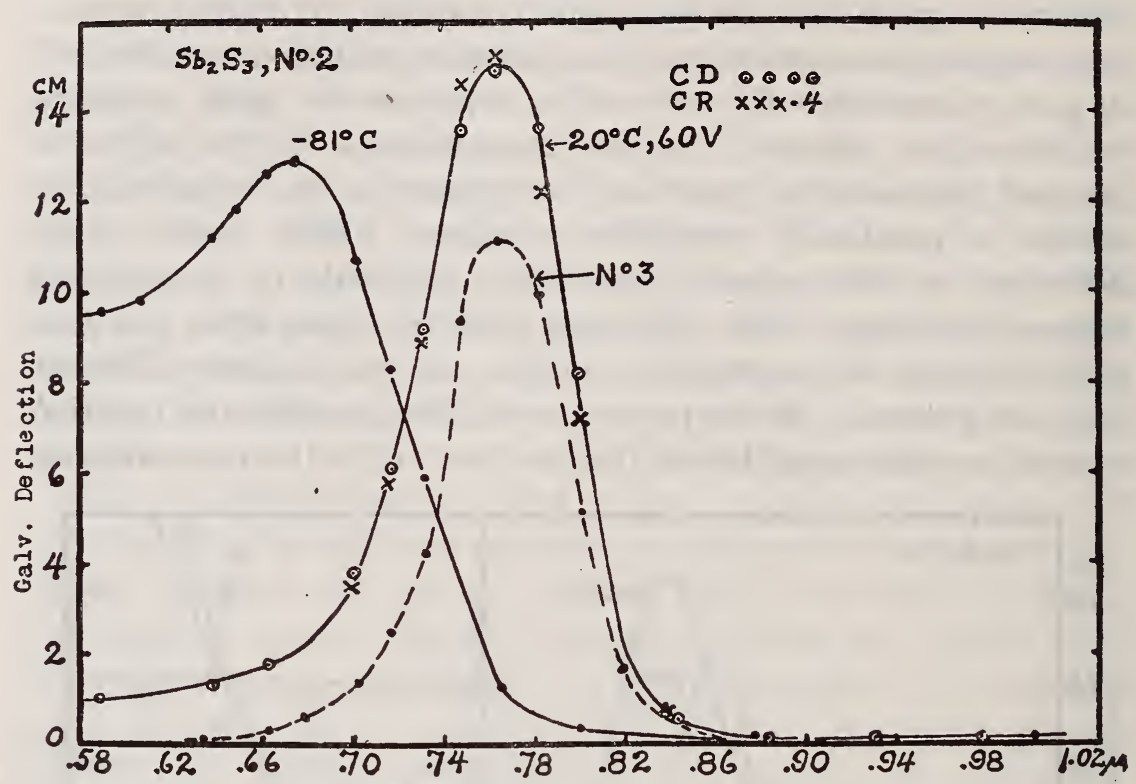

FIG. 3.-Effect of temperature upon the spectrophotoelectric sensitivity of stibnite

\section{EFFECT OF DIRECTION OF CURRENT THROUGH THE CRYSTAL}

The electric conduction of stibnite is unipolar. When a potential (6o volts) was applied to the crystal in a direction to cause the greatest dark conductivity $(C . D$.) the galvanometer deflection was over $65 \mathrm{~cm}$. On reversing the direction of the current $(C . R$.) the galvanometer deflection was only about $\mathrm{i} 6 \mathrm{~cm}$.

In Fig. 3 the circles $(\odot \odot \odot)$ represent the observations for the current direct $(C . D$.) while the crosses $(\times \times \times)$ represent the observations, magnified four times, when the current was reversed. When the fact that a correction had to be made for change in conductivity with time is taken into consideration, the agreement in the two curves is sufficiently close to conclude that the direction of the current through-that is, the polarization in-the crystal has no effect upon the spectrophotopositive reaction in stibnite. This will be noticed also in the photopositive reaction in molybdenite, in which, however, it was found that the direction of the current has a very marked effect upon the spectrophotonegative reaction. 


\section{A SPECTROPHOTONEGATIVE REACTION IN STIBNITE}

In connection with the present observations of a similar phenomenon in molybdenite, it is of interest to discuss the spectrophotonegative observations on stibnite made by Elliot. ${ }^{9}$ His observations, illustrated in Fig. 2, show that for wave lengths less than $0.657 \mu$ the deflections were negative, while for wave lengths greater than $0.657 \mu$ they are positive. As will be noticed presently in some parts of the molybdenite spectrum, he observed that the deflection was not purely negative, but that, on exposure of the crystal to radiation, the response (galvanometer deflection) was first positive, followed immediately by an equal negative deflection. Furthermore, whenever the deflection was negative, he observed an additional negative deflection immediately after shutting off the light. From his description of the reaction, curve A, Fig. 2, is given to illustrate this phenomenon. He found also that this photonegative reaction disappeared (but was not destroyed) at low temperatures. It does not appear that he tested the effect of increasing the voltage, which in the present work was found to affect the photonegative response. Although Elliot's data are fragmentary, they are sufficiently complete to show that the photonegative reaction in stibnite is of the same character as that observed in molybdenite.

\section{PHOTOELECTRIC REACTIONS IN SILVER SULPHIDE}

The spectrophotoelectric reaction of silver sulphide under various conditions of operation was described in a previous paper. ${ }^{10}$ In view of the fact that at room temperature the photoelectric response decreased after attaining a maximum, the first throw of the galvanometer, which was attained in about three seconds, was taken as a measure of the reaction of the crystal on exposure to radiation. At low temperatures this supposed electrolytic action seemed to disappear.

Subsequently, in connection with the photonegative reaction observed in molybdenite, ${ }^{11}$ a cursory examination of the mineral, acanthite, $\mathrm{Ag}_{2} \mathrm{~S}$, was made at various temperatures, ranging from -95 to $-140^{\circ} \mathrm{C}$, and for various applied potentials ranging from I 2 to I Io volts.

\footnotetext{
${ }^{9}$ Elliot, Phys. Rev. (2), 5, p. 62; 1915.

${ }^{10}$ B. S. Scientific Papers, 15, p. 231; I919.

11 Coblentz and Kahler, Jour. Wash. Acad. Sci., 9, p. 537; 1919.
} 
No spectral photonegative reaction similar to that of molybdenite was observed. Instead of the photopositive response, followed by a small photonegative effect (as observed in acanthite, at $20^{\circ} \mathrm{C}$ and as observed in molybdenite), it was found that on exposure to light even for only an instant, the galvanometer gave a momentarily negative throw of 2 to $5 \mathrm{~mm}$, followed by the positive deflection usually observed.

In order to verify these observations, a detailed series of measurements was made on sample No. 5, previously examined, and on a new sample, No. 6 . The observations made at $20^{\circ} \mathrm{C}$ were in good agreement with those made at $0^{\circ} \mathrm{C}$. However, the galvanometer was more steady at the lower temperature, and exact quantitative measurements were made only at low temperatures. These measurements will now be described.

\section{RESPONSE-TIME OBSERVATIONS}

In these tests the galvanometer and crystal were connected directly in series with a dry battery of about 5 volts. A typical illustration of the reaction-time, on exposure to a monochro-

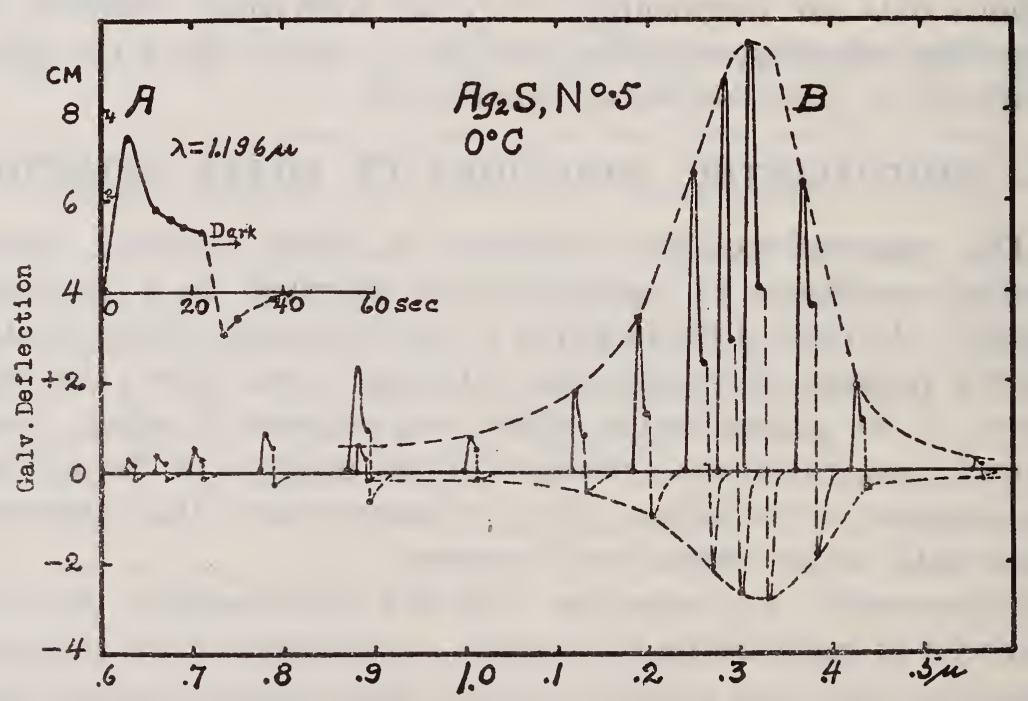

FIG. 4.-Photoelectric reaction-time curves of acanthite in different parts of the spectrum

matic radiation stimulus, is given in curve A, Fig. 4. The continuous part of curve $\mathrm{A}$ represents the response on exposure to radiation of wave length $1.196 \mu$ while the dotted part of the curve illustrates the recovery of the dark conductivity after exposure. In the main part of the illustration, Fig. 4, the abscissas of the response-time curves (for example, curve A) are illustrated 
diagrammatically at the different wave lengths used as radiation stimuli. The data from $0.6 \mu$ to $0.9 \mu$ were obtained with the (lamp) source of radiation operated on 4 amperes. For the observations from $0.9 \mu$ to $\mathrm{I} .5 \mu$ an equal energy spectrum was used.

The envelope, the dotted curve, $B$, through the maxima of these response curves, represents the spectrophotoelectric sensitivity of acanthite, previously published. The envelope of the negative deflections is also very interesting, as is also the line which could be drawn through the points representing the steady deflection attained just before shutting off the light. These observations are similar to those made on molybdenite, with this exception that the photonegative part of the response is not selective to wave length which obtains in molybdenite.

\section{EFFECT OF DIRECTION OF CURRENT}

Observations were made at $2 \mathrm{I}^{\circ} \mathrm{C}$ to determine the effect of changing the direction of the current through the crystal. On exposure to radiation when the current was reversed, $C . R$., the galvanometer deflections were much smaller than when the current passed directly, $C . D$., through the crystal. Nevertheless, the same positive-negative effect, illustrated in Fig 4, was observed for $C . R$. as for $C$. D., the only difference being in the magnitude of the deflection. The dark conductivity was also reduced for $C$. $R$. In fact, the photoelectric reaction in acanthite at $0^{\circ} \mathrm{C}$ seemed to depend merely upon the electric current flowing, and not upon any polarization effects inherent in the crystal.

\section{EFFECT OF TEMPERATURE}

In the previous investigation of silver sulphide it was found that with decrease in temperature the sensitivity is greatly increased and the maximum is shifted toward the short wave lengths. Moreover, the photonegative reaction seemed to disappear at low temperature. In the present tests it was found that although the large photonegative responses had disappeared, there occurred momentary reactions which required investigation.

Tests were made at -30 to $-102^{\circ} \mathrm{C}$, with various applied voltages. In a few instances when observations were being made at $-100^{\circ} \mathrm{C}$ on $2 \mathrm{I}$ volts, a pure negative deflection was obtained for $\lambda=0.5876 \mu$ (see molybdenite curve $37 \mathrm{~V}, \mathrm{Fig} .8$ ), while at $-45^{\circ} \mathrm{C}$, on $2 \mathrm{I}$ volts, a pure positive (see curve $\mathrm{I} 2 \mathrm{~V}, \mathrm{Fig} .8$ ) deflection was observed. Owing to difficulties in maintaining a constant temperature, it was not possible to determine whether or not this 
effect was selective to wave length, as observed in stibnite and molybdenite. Usually, the response was that of the typical example given in curve A, Fig. 4. At - Ior $^{\circ} \mathrm{C}$, for wave lengths 0.5876 to $0.88 \mu$, the response was marked by a "negative kick" on exposure, followed by a positive deflection, and a further positive deflection or "overshooting" ("positive kick") on shutting off the light. (See the left curve in Fig. 5.) For wave lengths in the region of I to I.4 $\mu$ the negative kick on exposure and the positive kick on shutting off the light were absent. In some respects the reaction appears to be selective to wave lengths greater than $\mathrm{I} \mu$.

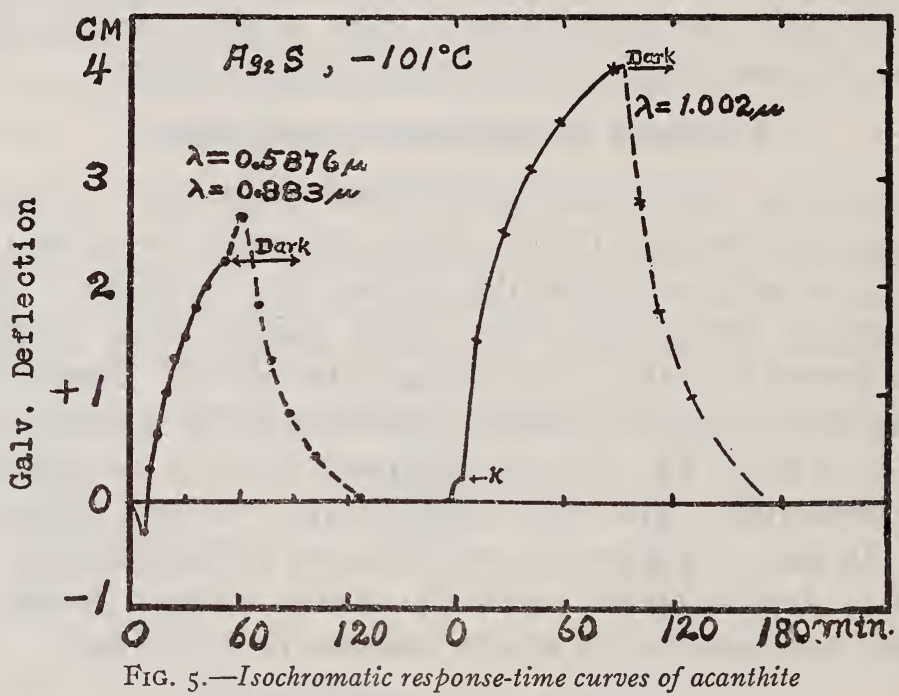

Instead of the slight negative deflection which was usually observed directly after exposure, the deflection started out positive, for radiation of wave lengths $\mathrm{I} .002 \mu$, Fig. 5, slackened in speed for a moment, then proceeded on its course to a maximum. The response seemed similar to that observed at short wave lengths, except that the slightly negative reaction manifested itself merely as a slackening of the speed of the positive reaction, and hence as a kink, $K$, in the response-time curve. These observations are illustrated at $K$ in Fig. 5 , and are of interest in connection with similarly unusual reactions observed in molybdenite. (See Fig. II.) In Fig. 5 the observed galvanometer deflections for radiation of wave length $\mathrm{I} .002 \mu$ were twice the indicated value. 


\section{PHOTOELECTRIC REACTIONS IN MOLYBDENITE}

The present investigation of molybdenite is chiefly upon samples previously examined..$^{12}$ In connection with the quantitative measurements on sample No. I, which are described in this paper, a qualitative examination was also made of the spectrophotoelectric sensitivity of samples Nos. 2, 4, 5, and 8, as affected by temperature, applied voltage, and direction of current through the crystal. None of these samples showed the photonegative properties found in No. I. On reversal of the current through the crystal the photoelectric responses appeared to be proportional to the dark current, as previously observed. These crystals did not appear to have regions of photonegative sensitivity such as were found in sample No. I.

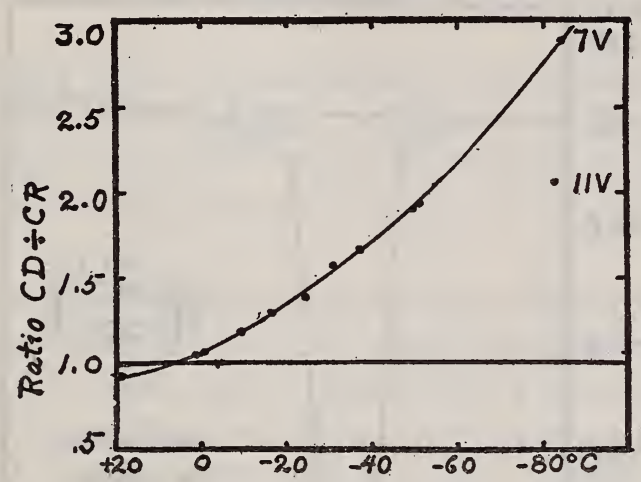

FIG. 6.-Ratios of electrical conductivities with temperature

\section{GENERAL OBSERVATIONS}

Under this caption are recorded observations which are of a miscellaneous nature.

(a) UNIPOLAR Conduction.-The great difference in electric conductivity which is observed on reversal of the current through some crystals has been observed by others and recorded in treatises on mineralogy. In the previous paper (loc. cit.) it was shown that this phenomenon was marked in samples of molybdenite which have a high specific resistance.

The present observations, on sample No. I, are illustrated in Fig. 6, which gives the ratios of the dark currents (the galvanometer deflections) $C . D$. to $C . R$., on 7 volts, at different temperatures. This curve shows that the direction of greatest conductivity depends upon the temperature, a phenomenon which appears worthy of further study. 
The transition temperature seemed to be a little above the melting point of ice, say, $+5^{\circ} \mathrm{C}$. The test was made with ice and also with liquid air as the cooling medium. The $20^{\circ} \mathrm{C}$ point (room temperature) was observed repeatedly, during this investigation, as was also the ratio at $-82^{\circ} \mathrm{C}$. Hence there is no question of the reversal occurring, though the exact temperature at which the transition occurs may be in error.

The effect of varying the voltage is also of interest. At $-82^{\circ}$ $\mathrm{C}$, on I. 3 volts the ratio $C . D . \div C . R .=6$, while on II volts the ratio decreases to 2.I, as indicated in Fig. 6.

(b) Photoelemctric Sensitivity of DifFerent Parts of the CRYSTAL.-An examination was made of the photosensitivity of different parts of sample No. 1 , with results as illustrated in Fig. 7 .

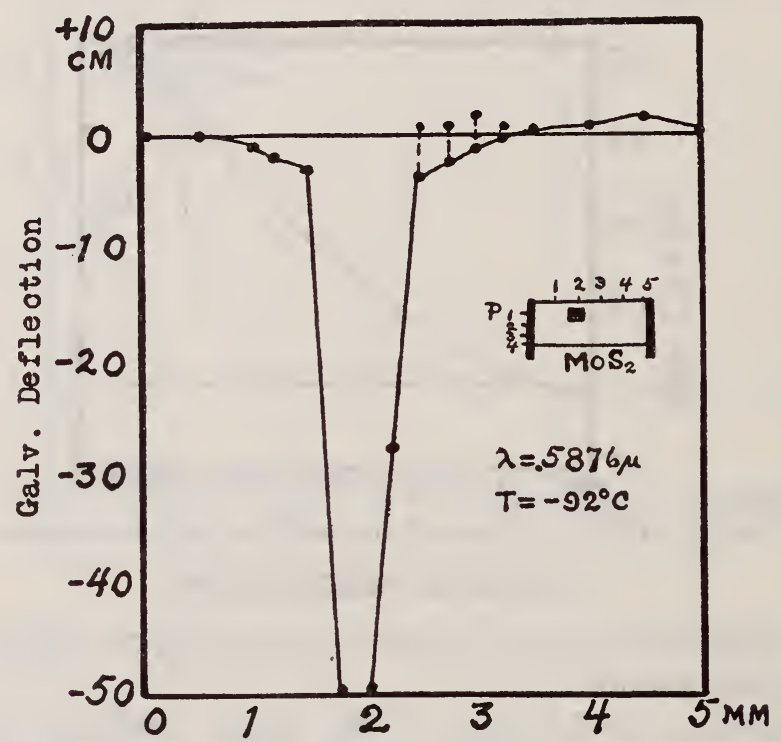

FIG. 7.-Exploration of the photoelectric sensitivity of a crystal

The sample was soldered to copper electrodes. The soldered portions were covered with heavy cardboard to prevent light from impinging upon them. The length of the crystal, which was free from solder, was about $5 \mathrm{~mm}$, as indicated in Fig. 7 .

In the preliminary examination of the sensitivity of the surface of the crystal, the spectrometer slit was projected lengthwise horizontally, in the various positions $\mathrm{P}_{1}, \mathrm{P}_{2}$, etc., indicated in the vertical scale, Fig. 7 .

After making this examination the crystal was covered with a heavy cardboard having a slit $5 \mathrm{~mm}$ long and $0.5 \mathrm{~mm}$ wide. This slit was placed so as to expose the most active photonegative part 
of the crystal. The image of the spectrometer slit, $0.5 \mathrm{~mm}$ wide, was then projected vertically across this slit, and an exploration was made of the photoelectric sensitivity along the length of the crystal, as indicated in the horizontal scale $1,2,3$, etc., in Fig. 7 .

As shown in the curve, Fig. 7, the maximum negative photoelectric response was obtained in the position $P_{1}$ at a distance of about $1.75 \mathrm{~mm}$ from the left end of the crystal. This point of maximum sensitivity (shown here as a small dark rectangular area) is designated in subsequent illustrations as $P_{1}-1.75$.

In the position $\mathrm{P}_{1}-3$, the photoelectric response was first positive, followed by a negative deflection. Some very interesting data on the effect of voltage, etc., were obtained on this part of the crystal, which appears to be the region of transition from the pure photonegative to the pure photopositive reaction which occurs at $\mathrm{P}_{1}-4.5$.

Along the lower edge, $\mathrm{P}_{4}$, the photoelectric response was always positive, whatever the applied voltage, temperature, or wave length of the light stimulus. Hence no detailed examination was made of the spectrophotoelectric sensitivity of this part of the crystal.

The present investigation relates primarily to the effect observed (I) when a narrow strip along the whole length of the crystal, at $\mathrm{P}_{1}$, was exposed to light, and (2) when only a small portion of this strip, $0.5 \mathrm{~mm}$ long and $0.5 \mathrm{~mm}$ wide, is exposed to radiation. The latter condition is practically that of a short crystal which is connected in series with a very high resistance.

The large responses observed show the very high intrinsic sensitivity that obtains in this small spot. If large areas can be prepared having such a high intrinsic sensitivity, a cell of extraordinary sensitivity and great usefulness will be at hand.

\section{ISOCHROMATIC OBSERVATIONS}

There are so many variables to be considered that one has to proceed with great care in order to determine the effect of each one. Under this caption data are given on the electric responses obtained, using radiation of wave length $0.5876 \mu$ as the stimulus, and varying the applied potential, temperature, etc.

(a) Photoelectric Response-TIME CURVES For DifFerent VolTAgES AND CONSTANT TEMPERATURE.-The first observations, illustrated in Figs 8 and 9, were made with the assistance of $\mathrm{H}$. Kahler and published as a preliminary report. ${ }^{13}$ For this purpose

2056 Coblentz and Kahler, Proc. Wash. Acad. Sci. 9, p. 537: I9I9. 
the crystal was exposed lengthwise along the line $\mathrm{P}_{1}$; the direction of the current being $C$. D.

In Fig. 8 the continuous part of the curves show the movement of the galvanometer needle with time, when the crystal was exposed to radiation, while the dotted part of the curve shows the recovery after exposure.

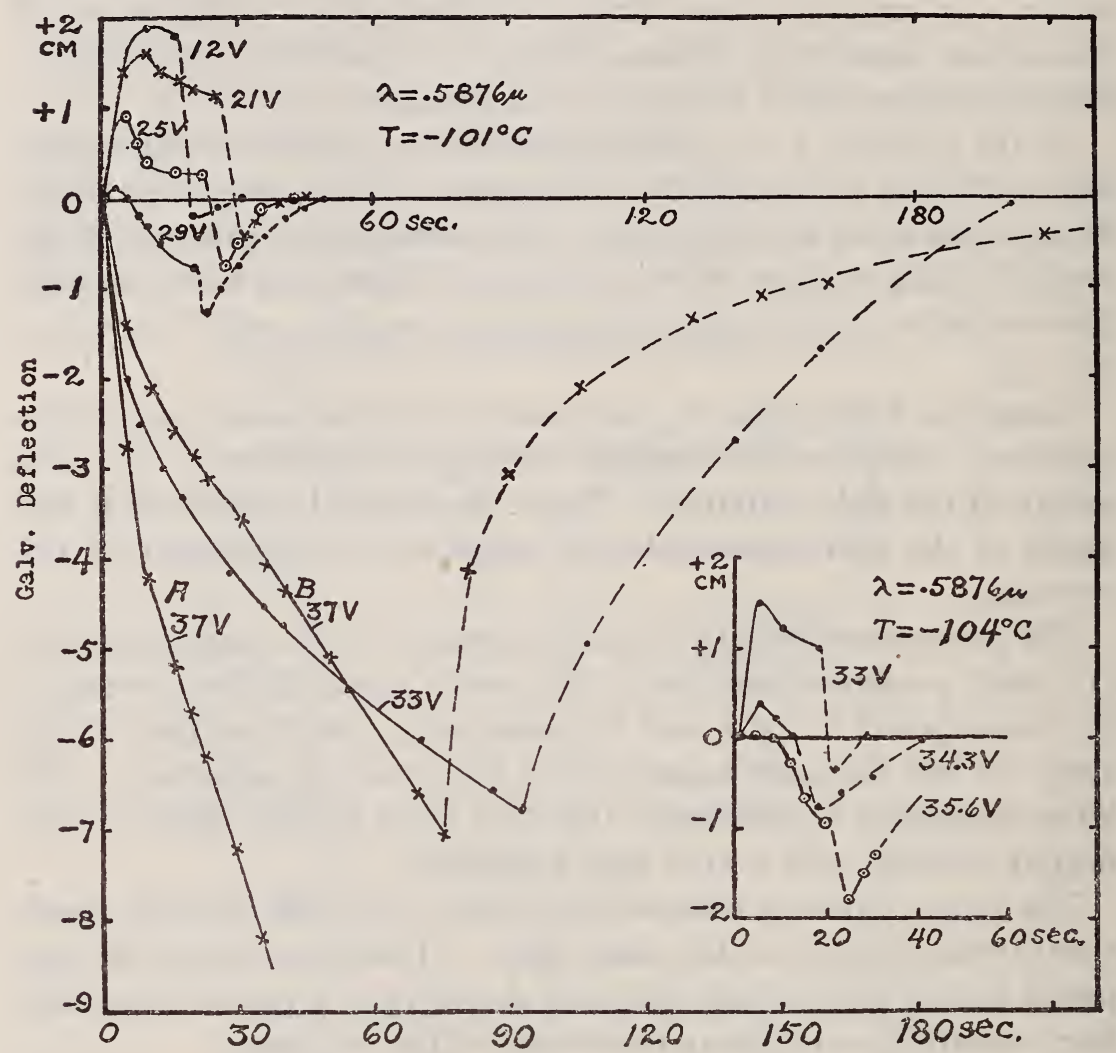

FIG. 8.-Isochromatic, photoelectric response-time curves as a function of the applied voltage (Molybdenitc)

These curves show that, with increasing voltage, at $-\mathrm{ror}^{\circ} \mathrm{C}$, the deflection changed from a purely positive, on $\mathrm{I} 2$ volts, through the intermediate stages to a purely negative deflection, on 33 volts. In Fig. 8, curve B, for 37 volts, is drawn to one-half the scale of the rest of the curves.

It may be noted that the time to obtain a maximum response is greatly prolonged when the purely negative reaction is obtained. This is similar to the long time required for equilibrium of the positive response previously described for wave lengths at I $\mu$. 
The data for - $104^{\circ} \mathrm{C}$, given in Fig. 8, are interesting in showing that, on 35.6 volts, the sample was exposed for eight seconds before the galvanometer showed an appreciable deflection, which was then negative. An almost similar example is shown in the curve for 29 volts, Fig. 8 , in which the initially positive throw was barely perceptible.

The data of Ries (loc. cit.) on selenium, shown in Fig. I, are evidently of a similar nature, though he did not investigate the effect of the voltage upon the photonegative response.

It does not appear that moisture plays any important part in the photonegative response, because the crystal, after having been in an evacuated inclosure for over six months, gave the same reaction on repeating the test. Moreover, if this effect is caused by moisture, it is not clear why it should occur in one spot. Subsequent to the observations given in Fig. 8, this sample was repeatedly removed from the inclosure, to be replaced by samples of other substances-for example, silver sulphide and stibniteand, on remounting, the photonegative response was always obtained, as illustrated in Figs. I I, I2, etc.

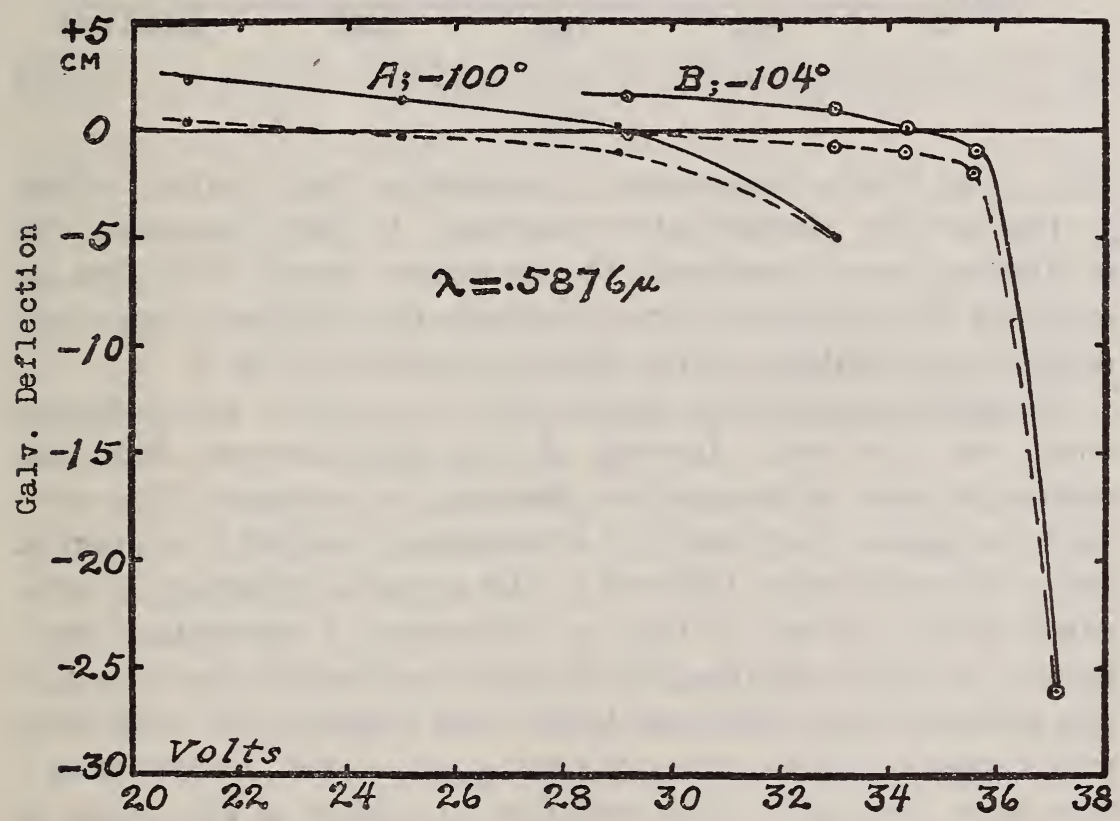

FIG. 9.-Critical voltage; isochromatic photoelectric sensitivity of molybdenite as a function of the applied voltage

(b) Variation of Photoelectric Sensitivity with Voltage AT CONSTANT TEMPERATURE.-In Fig. 9 the effect of voltage upon 
the photoelectric response is illustrated in a different manner from that of Fig. 8. In fact, it is a condensed illustration of some of the data given in Fig. 8. The continuous curve represents the maximum steady deflection at different voltages. The dotted curve represents the negative deflection on closing the shutter.

Curve A represents the observations at $-100^{\circ} \mathrm{C}$. and curve $\mathrm{B}$ at $-104^{\circ} \mathrm{C}$. They show that with decrease in temperature the critical voltage increases. As shown in curve $B$, an additional dry battery of 1.3 volts, added to the 35.6 volts already applied, greatly increased the photonegative response.

After a lapse of six months, the sample having been remounted in the container, similar observations were made at $-16 \mathrm{I}^{\circ} \mathrm{C}$,

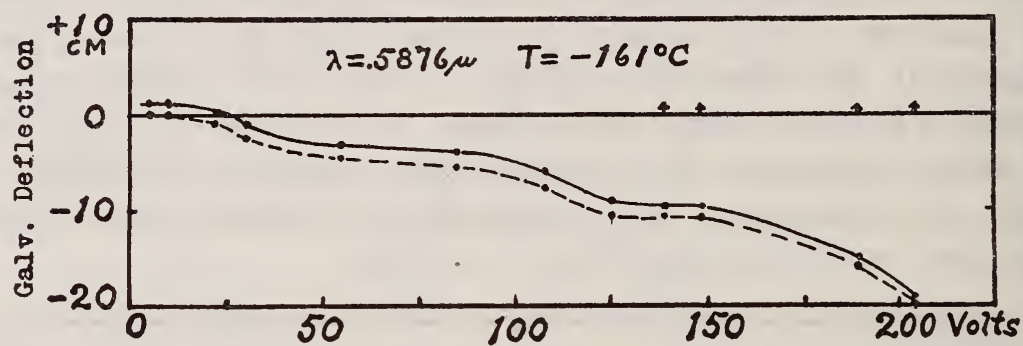

FIG. Io.-Isochromatic photoelectric response in molybdenite as a function of the applied voltage

Fig. Io, at which temperature it required a much higher voltage to produce the photonegative reaction. In this illustration the continuous curve represents the maximum steady deflection on exposure and the dotted curve represents the additional (negative) deflection on shutting off the light, as observed in Fig. 8.

On applying potentials greater than 125 volts, a new phenomenon was observed. Instead of the galvanometer deflection starting at once in the negative direction, on exposure of the crystal to radiation, there was first a momentary kick of 2 to $3 \mathrm{~mm}$ in the positive direction, followed by the negative deflection, as indicated by the arrows, in Fig. Io. Moreover, a momentary reexposure just after shutting off the light accelerated the return of the galvanometer deflection to its zero position and sometimes even caused a positive throw of I to $I .5 \mathrm{~cm}$. This "overshooting" was more thoroughly examined five days later as illustrated in Fig. II. It may be that in some cases the crystal had not attained equilibrium after exposure, and that some of these small positive throws of the galvanometer were the result of "overshooting" in accelerating the recovery from the first exposure. 
However, further investigation will be required to determine the effect of the overshooting which results from reexposing the substance before it has fully recovered from the effects of the preceding exposure.

In view of the fact that the electric resistance increases rapidly with decrease in temperature, and also that the photosensitive material occupies only a small part of the sample examined, it is hardly permissible to attribute some of the observed phenomena to the temperature. For example, at any one temperature the change from a photopositive to a photonegative response can be obtained by simply changing the voltage, or, keeping the voltage constant, say, on 40 volts, by changing the resistance in the external circuit. Thus, on inserting 5000000 to 10000000 ohms in series, which reduces the current flowing, the pure photonegative deflection previously obtained on 40 volts is changed to a photopositive response similar to that which is observed on 5 to ro volts. In other words, it appears that this photonegative property is a function of the electric current flowing through the crystal.

(c) Overshooting-Voltage Constant, Temperature VariABLE.-At various times during the course of this investigation, while the crystal was recovering from an exposure, a peculiar unsteadiness of the galvanometer was observed. The suspended coil would execute a series of vibrations which were irregular, and of greater magnitude than could result either from a lack of damping of the coil, or from unsteadiness of the temperature of the crystal. The whole seemed to be the result of an irregular recovery of the electrical conditions of the crystal, after exposure to radiation. Moreover, this unsteadiness seemed to occur only at moderately low temperatures, say, $-20^{\circ} \mathrm{C}$.

A special series of observations was therefore taken in which the scale readings were noted as quickly as they could be read. A photographic method would have been better. However, the observations are consistent, showing that, in the temperature range from - io to $-25^{\circ} \mathrm{C}$., the recovery after exposure is very irregular. This is especially conspicuous at about $-20^{\circ} \mathrm{C}$, Fig. I I, where, on recovery, the deflection overshoots in the positive direction by an amount as large as was the negative deflection which was caused by exposure of the crystal to light. Moreover, these oscillations are repeated and do not appear to be the result of the lack of damping of the galvanometer coil. 
The peculiar character of these oscillations during recovery is illustrated in Fig. I $\mathrm{I}$, in which the horizontal axis of coordinates represents the temperature and diagrammatically also the time of the response as given in Fig. 8. The point of beginning of the deflection represents the temperature. In this experiment the voltage was kept constant $(22.5 \mathrm{v})$ and the temperature was varied. The curves represent the average of two to four sets of observations at any one temperature.

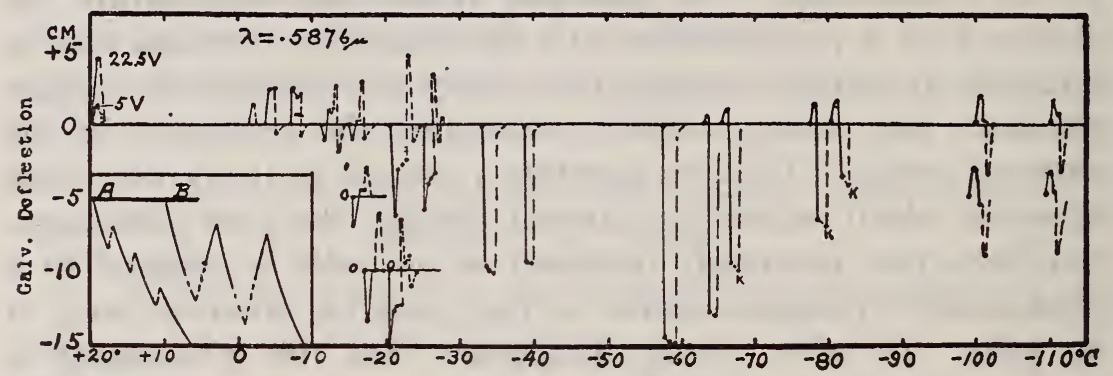

FIG. II.-Isochromatic, photoelectric reaction-time curves of molybdenite at various temperatures

At $-\mathrm{II}^{\circ} \mathrm{C}$, on exposing the crystal to radiation, the deflection was first negative, then turned to positive. On closing the shutter (dotted part of the curve) the galvanometer gave an additional positive deflection followed by an equally large negative deflection, and then returned to zero. This first throw on opening the shutter is just the opposite of that observed in Fig. 8, but is similar to the reaction observed in silver sulphide, Fig. 5 , at $-101^{\circ} \mathrm{C}$. At $-17^{\circ} \mathrm{C}$ on exposure of the crystal there was first a negative throw of $3.5 \mathrm{~cm}$, after which the deflection returned to zero. On shutting off the light there was first a positive throw of about 4 $\mathrm{cm}$ after which the deflection returned to zero.

At -20 to $-25^{\circ} \mathrm{C}$ the deflection, on exposure, was negative, similar to the positive deflection observed in Fig. 8; but there were large oscillations, with positive deflections, during the period of recovery after exposure. In fact, aside from the oscillations during recovery the reaction seems just the reverse of that observed in curve $2 \mathrm{rV}$, Fig. 8.

At -33 to $-57^{\circ} \mathrm{C}$ the deflection was purely negative, as observed in Fig. 8 for a higher voltage and lower temperature.

At -63 to $-80^{\circ} \mathrm{C}$, on exposure of the crystal, there was first a momentary positive kick of 0.5 to $1.5 \mathrm{~cm}$ followed by the usual negative deflection. On shutting off the light there was a further 
negative kick as previously observed at $-\mathrm{I}^{6} \mathrm{I}^{\circ} \mathrm{C}$ (see Fig. Io), after which the deflection returned to zero.

At -100 to $-\mathrm{IIO}^{\circ} \mathrm{C}$ the deflections on exposure were first positive returning to practically zero, or becoming slightly negative. On shutting off the light there was a negative deflection, then recovery to zero. This is just the opposite of the effect observed at $-17^{\circ} \mathrm{C}$, but is in agreement with the previous observations at - Ior to $-104^{\circ} \mathrm{C}$, Fig. 8. In fact, it is an excellent verification of the measurements made six months earlier under entirely different conditions (see curves for 29 and 34 volts, Fig. 8 ), the crystal, in the meantime, having been removed several times from the container.

As already mentioned, it was observed in earlier experiments, especially at $-\mathrm{I} 6 \mathrm{r}^{\circ} \mathrm{C}$ on 203 volts (Figs. ro and $\mathrm{I} \mathrm{r}$ ), that, on reexposing the crystal to radiation before complete recovery from the effect of the previous exposure, the rate of recovery appeared to be accelerated; for example, suppose the deflection is of the positive-negative type illustrated in curve $29 \mathrm{~V}$, Fig. 8 . On shutting off the light, the deflection continues in the negative direction for a moment, then starts in the positive direction, as indicated in the dotted part of curve B, Fig. I r. If at this moment the crystal is illuminated for an instant, the deflection is accelerated in the positive direction, after which it again travels in the negative direction, as indicated by the continuous part of the line, B, Fig. II. However, if the deflection is purely negative (similar to curve $37 \mathrm{~V}$, Fig. 8), the reaction is slower, there is no deflection in the positive direction, and the complete negative deflection can be built up by successive exposures, as illustrated in curve A, Fig. II.

In some instances, at -60 to $-160^{\circ} \mathrm{C}$, it was observed that the momentary positive throws illustrated in Figs. Io and I I were produced when insufficient time was given for recovery from the effects of the previous exposure. Unfortunately, no special examination was made to determine whether the small positive throws-for example, in Fig. ro-which preceded a negative deflection, arise in all cases from incomplete recovery from the effects of a previous exposure to radiation. The extensive data, covering a long period of investigation (see Fig. 14), seem to indicate that the phenomenon is not the result of lack of recovery from a previous exposure. 


\section{SPECTRAL OBSERVATIONS}

Under this caption data are given on the photoelectrical reaction produced by radiation of different wave lengths, when the temperature of the crystal is kept constant. Most of the observations relate to the visible spectrum, where the photonegative reaction occurs.

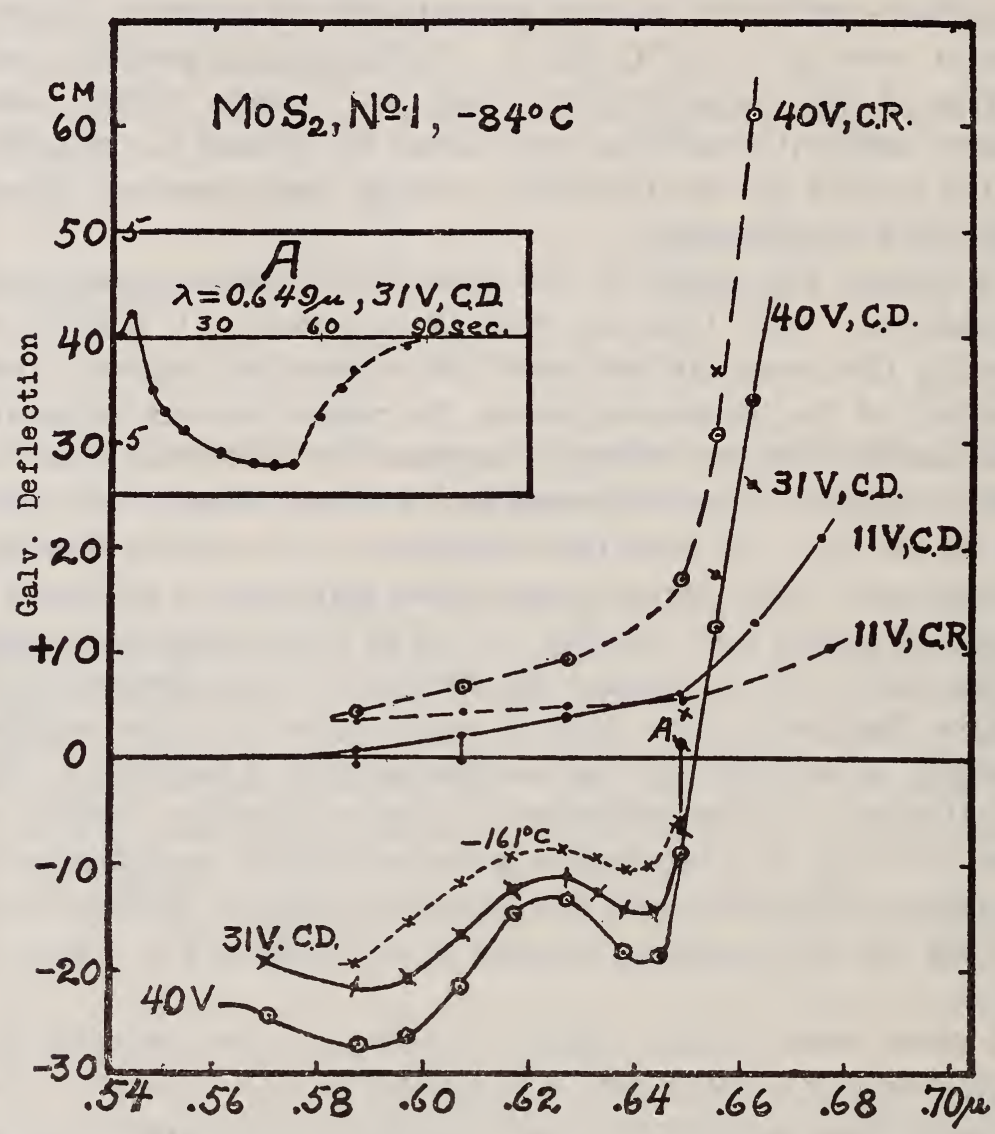

FIG. 12.-Spectrophotoelectric sensitivity curves of molybdenite as a function of the direction of the current through the crystal

(a) VARIATION OF SPECTROPHOTOELECTRIC SENSITIVITY WITH VolTAGE AND Direction OF CURRENT.-In Fig. I2 are given a series of curves showing the change in spectrophotoelectric sensitivity produced at $-84^{\circ} \mathrm{C}$, when the applied potential is increased from II to 40 volts; also when the direction of the current is reversed (C. D to $C . R$ ) through the crystal. In the latter case, no direct photonegative reaction was observed. However, it is present 
as is to be inferred from the measurements at $0.5876 \mu$ where the deflections are practically the same on II and 40 volts $C$. $R$.

On IIV, C. $D$, with increase in wave length, the deflections become more free from the photonegative effect. On $40 \mathrm{~V}, C . D$, the reaction is photonegative for wave lengths up to $0.647 \mu$. On 3 I volts, as shown at A, Fig. I2, the reaction for wave length $0.649 \mu$ is initially photopositive as previously observed in Fig. 8.

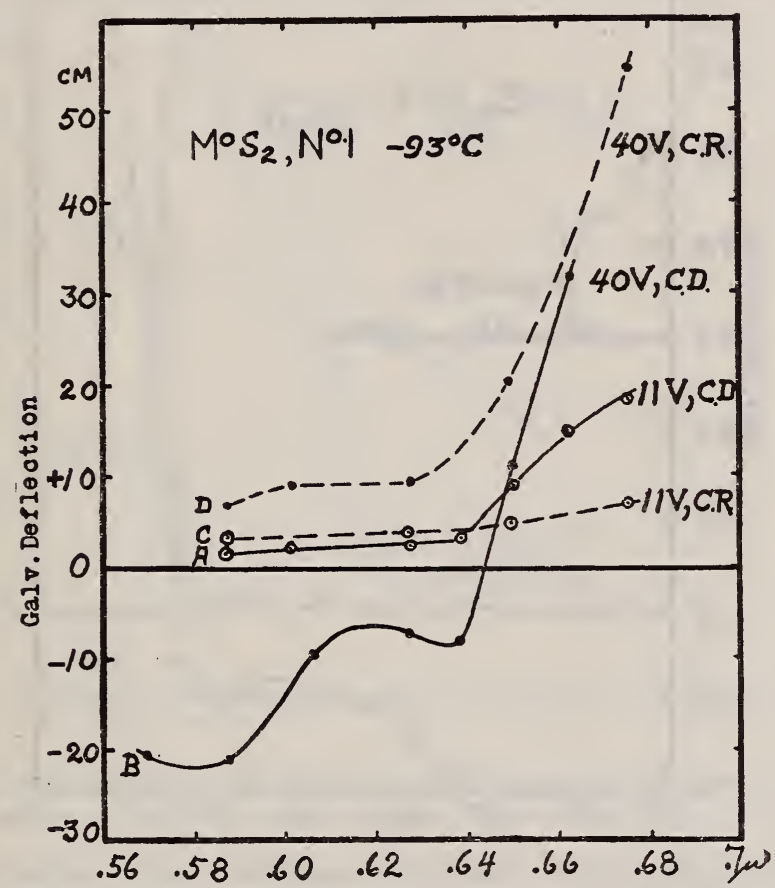

FIG. I3.-Effect of direction of current upon spectrophotoelectric sensitivity

In the preliminary tests it was found that, keeping the temperature constant, the region of transition in the spectrum in which the action changes from photonegative to photopositive is very narrow, being less than $0.001 \mu$. It will be noticed on a subsequent page that this neutral point shifts a little with change in temperature.

Further observations on these same voltages, but at a temperature of $-93^{\circ} \mathrm{C}$ instead of $-84^{\circ} \mathrm{C}$ are illustrated in Fig. I3, which shows that the critical voltage is raised and the photonegative reaction is decreased, as observed in Fig. 9. On IIV, $C$. $D$, the deflection was entirely positive.

The data observed at $-16 \mathrm{I}^{\circ} \mathrm{C}$, and $203 \mathrm{~V}, C$. D, Fig. I4, are unusual in that, on exposure of the crystal to radiation, there was 
first a momentary positive reaction followed by the negative deflection; and, on shutting off the light, there was a further negative throw of the galvanometer. These peculiar reactions are indicated, to scale, by the arrows in Fig. 14 . Similar observations at -60 to $-80^{\circ} \mathrm{C}$ are illustrated in Fig. I I, indicating that this is a function of the current flowing, at a given temperature.

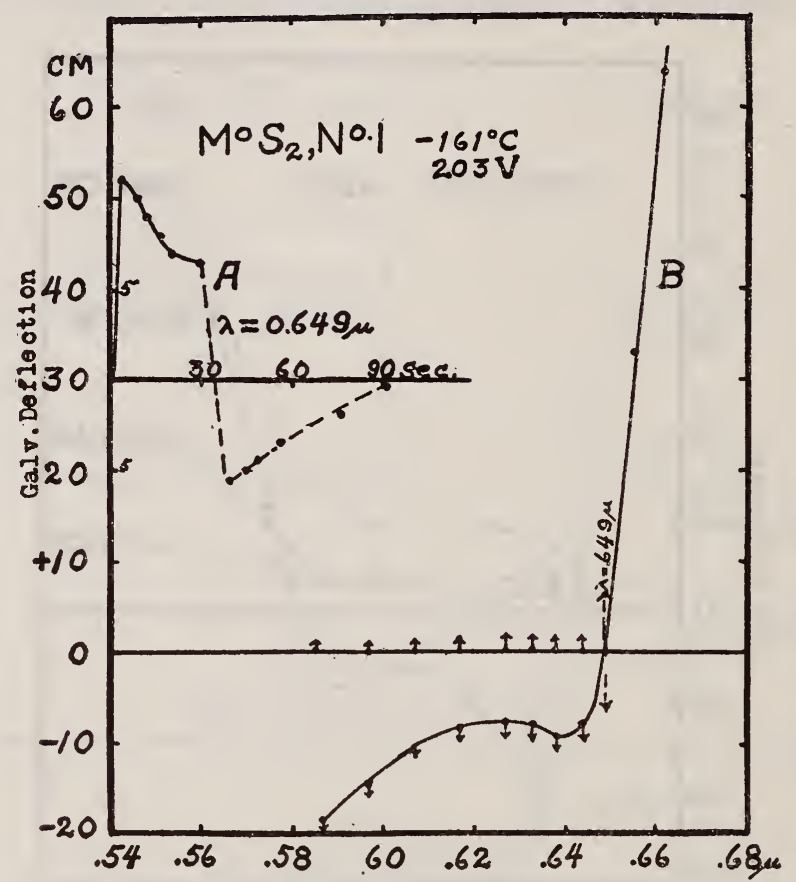

FIG. 14.-Photoelectric sensitivity in molybdenite at low temperature

The response-time curve for wave length $0.649 \mu$ given in $A$, Fig. I4, is of interest in comparison with a simliar curve in Fig. I2, also with curve $2 \mathrm{I} V$, Fig. 8. In Fig. 12 the deflection is almost purely negative. This is to be expected in view of the lower critical voltage at the higher temperature.

In view of the fact that the question may arise as to whether the data are reproducible it is relevant to add that an interval of II days elapsed between the observations illustrated in Fig. I2 and those of Fig. I3; the crystal, in the meantime, having been removed from the vacuum container to permit examination of the samples of stibnite already described.

In Fig. I 5 is portrayed the spectrophotoelectric reaction throughout the whole of the spectrum to which molybdenite reacts. The potential was kept at II volts and the temperature at $-84^{\circ} \mathrm{C}$. 
The ratio of the dark currents (the galvanometer deflections) for $C . D$. and $C . R$. was 2.32 . The observed photoelectric reactions for the current $C . R$. are plotted to scale, and the deflections observed for $C$. $D$. are divided by 2.32. On this voltage, for $C$. $D$, there is a slight photonegative reaction at $0.5876 \mu$ on shutting off the light, as indicated in Fig. I5.

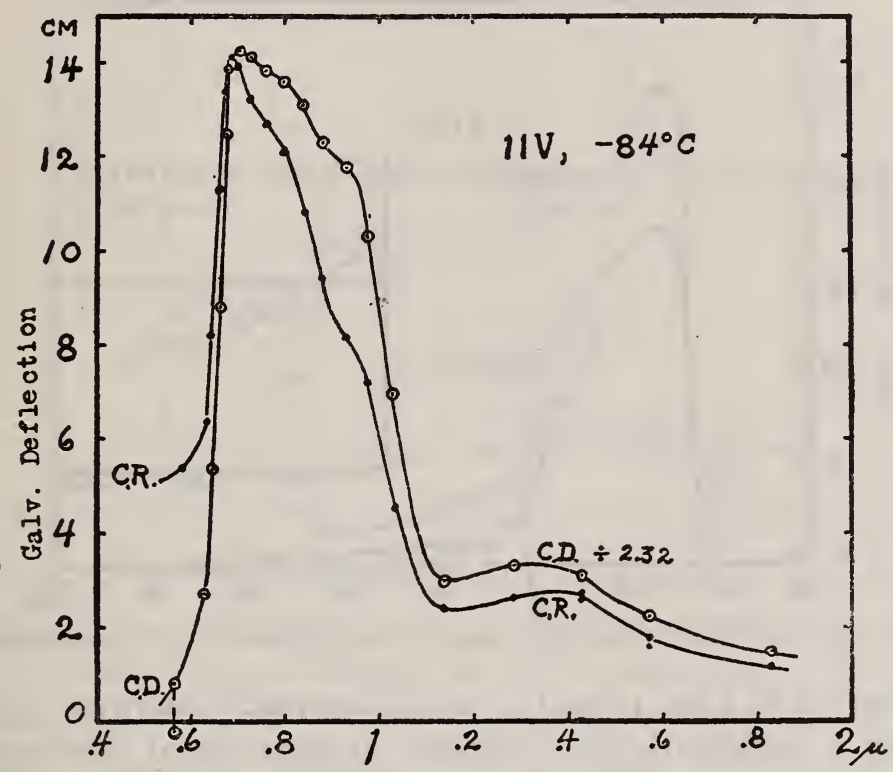

FIG. I5.-Isothermal spectrophotoelectric sensitivity of molybdenite as a function of the direction of the current through the crystal

From these curves it appears that the photonegative action has no marked effect beyond $0.8 \mu$ in the infra-red. This will be shown to better advantage in Fig. 20, where the applied potentials are selected so as to give the same dark currents in the two directions through the crystal.

In Fig. I 6 curves are given showing the spectrophotoelectric sensitivity of molybdenite at -125 and $-178^{\circ} \mathrm{C}$; also isochromatic observations at $-178^{\circ} \mathrm{C}$ for different voltages. The isochromatic curves are similar to those observed at higher temperatures, Fig. 8 , the only difference being the higher critical voltage, as previously noted. For example, at $-178^{\circ} \mathrm{C}$, on 60 volts, the reaction, on shutting off the light stimulus, is slightly negative at $0.5876 \mu$, whereas only i I volts was required to produce a similar effect at $-84^{\circ} \mathrm{C}$, Fig. I 5 .

The isothermal curves given in Fig. I 6 were observed in order to find the effect of a large dispersion upon the sharpness of the 
maxima of sensitivity. These curves show that the maxima and minima are not much more prominent, but they may be more numerous, than previously observed. But this does not demonstrate whether, with decrease in temperature, the maxima become more numerous or whether the total number is constant but merely closer together.

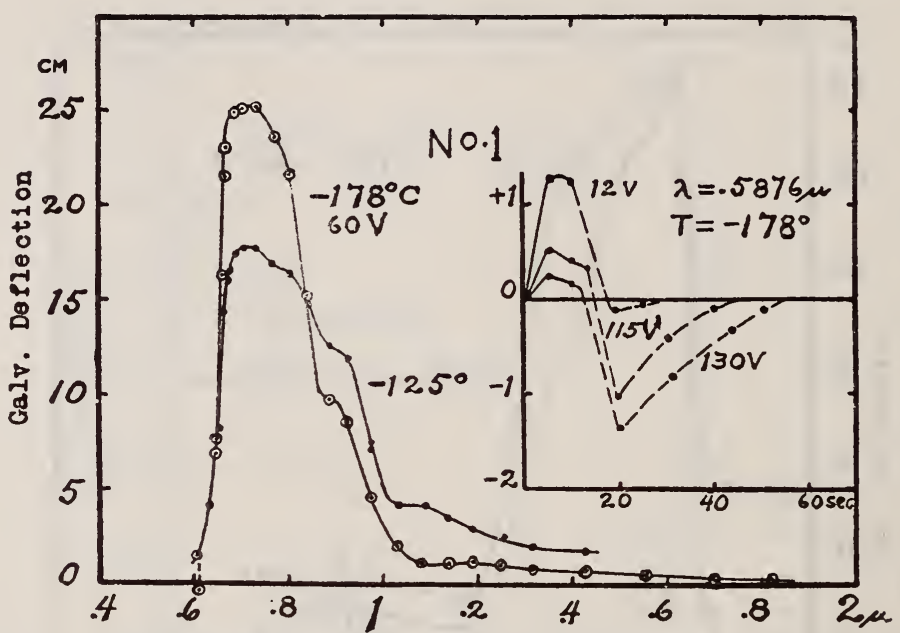

FrG. 16.-Photoelectric sensitivity curves of molybdenite at low temperatures

The curves in Figs. 15 and 16 are of interest in showing how, by applying a sufficiently low voltage, an isothermal photoelectric response curve can be obtained in which the reaction appears to be entirely photopositive throughout the whole spectrum.

(b) Variation of Photoelectric Reaction with Intensity OF THE Radiation Stimulus.-The photonegative response curves given in Figs. 12 and 13 are interesting in that there appear to be two minima, at wave lenghts of about 0.58 and $0.64 \mu$, respectively. This does not appear to be attributable entirely to the small band of selective reflection previously observed in molybdenite. $^{14}$ It was, therefore, important to examine the reaction caused by light stimuli extending into the violet. This necessitated reducing the intensity of the stimulus to one-seventh that previously used. The lamp was calibrated for equal energy, but no attempt was made to compensate for the loss by selective reflection (and transmission), which occurs in this part of the spectrum. For it was found on preliminary tests that increasing the intensity to compensate for this loss, which is less than ro per 
cent, did not affect the uniformity of the spectrophoto-electric reaction curve in the region of 0.45 to $0.55 \mu$.

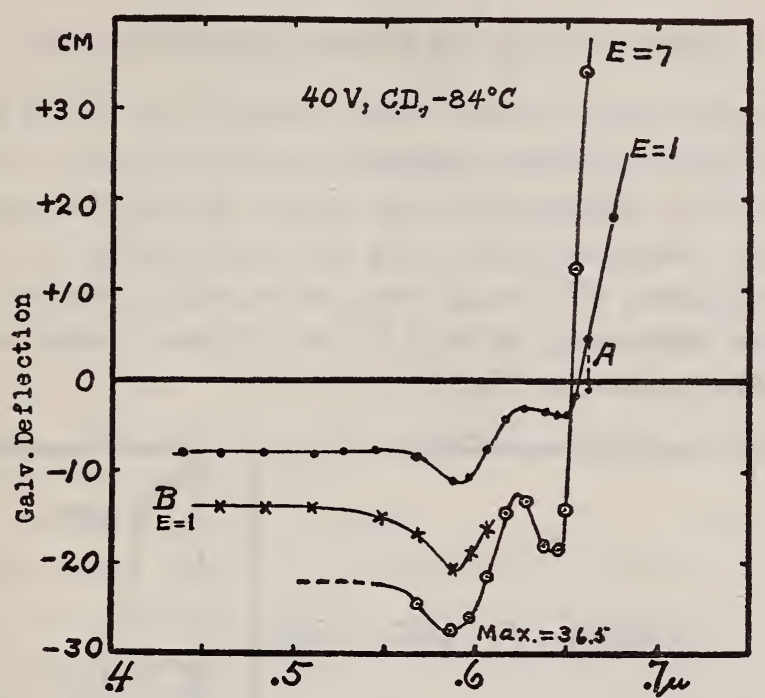

FIG. 17.-Effect of intensity of radiation upon the photonegative response

In Fig. I 7 the spectrophotoelectric observations are extended throughout the spectrum to $0.44 \mu$ in the violet. The curves show two well-defined minima in the orange-red of the visible spectrum, while in the violet the reaction seems to be quite uniform. This was verified in a subsequent examination. (See Fig. 19.)

In Fig. I 7 the curve for the intensity, $E=7$ is similar to the one for the radiation stimulus, $E=\mathrm{I}$. For the lower intensity the reaction on shutting off the light is still partly photonegative at wave length $0.662 \mu$, as indicated at $\mathrm{A}$ in Fig. I7. Evidently, the neutral point of spectrophotoelectric activity is a function of the temperature of the material and the intensity of the radiation stimulus.

On the same day when curve $E=\mathbf{I}$ was obtained, the maximum negative deflection for $E=7$ was $36.5 \mathrm{~cm}$ at wave length $0.5976 \mu$, giving a ratio of $E_{7}: E_{1}=36.5: \mathrm{II}=3.32$. The square root of $E_{7}: E_{1}=2.645$. From this, it appears that the "square-root law" does not represent the photonegative reaction, as was found in previous papers, which dealt with the photopositive reaction.

Curve B, Fig. I 7, shows the observations on the isolated photonegative spot (Fig. 7) using 40 volts and $E=\mathrm{I}$. This curve, 
which was obtained after dismounting the apparatus and recalibrating the lamp, verifies the foregoing observations. (See Fig. 19.)

\section{OBSERVATIONS ON A PHOTONEGATIVE SPOT}

The foregoing data pertain to the condition in which the radiation stimulus was applied lengthwise to the crystal. Under the present heading illustrations are given of the reaction of the isolated spot designated $P_{1}-\mathrm{I} .75$ depicted in Fig. 7 . In these tests the emergent slit image was projected crosswise upon the crystal, thus irradiating an area 0.5 by $0.5 \mathrm{~mm}$, shown as a small dark rectangular spot in Fig. 7 .

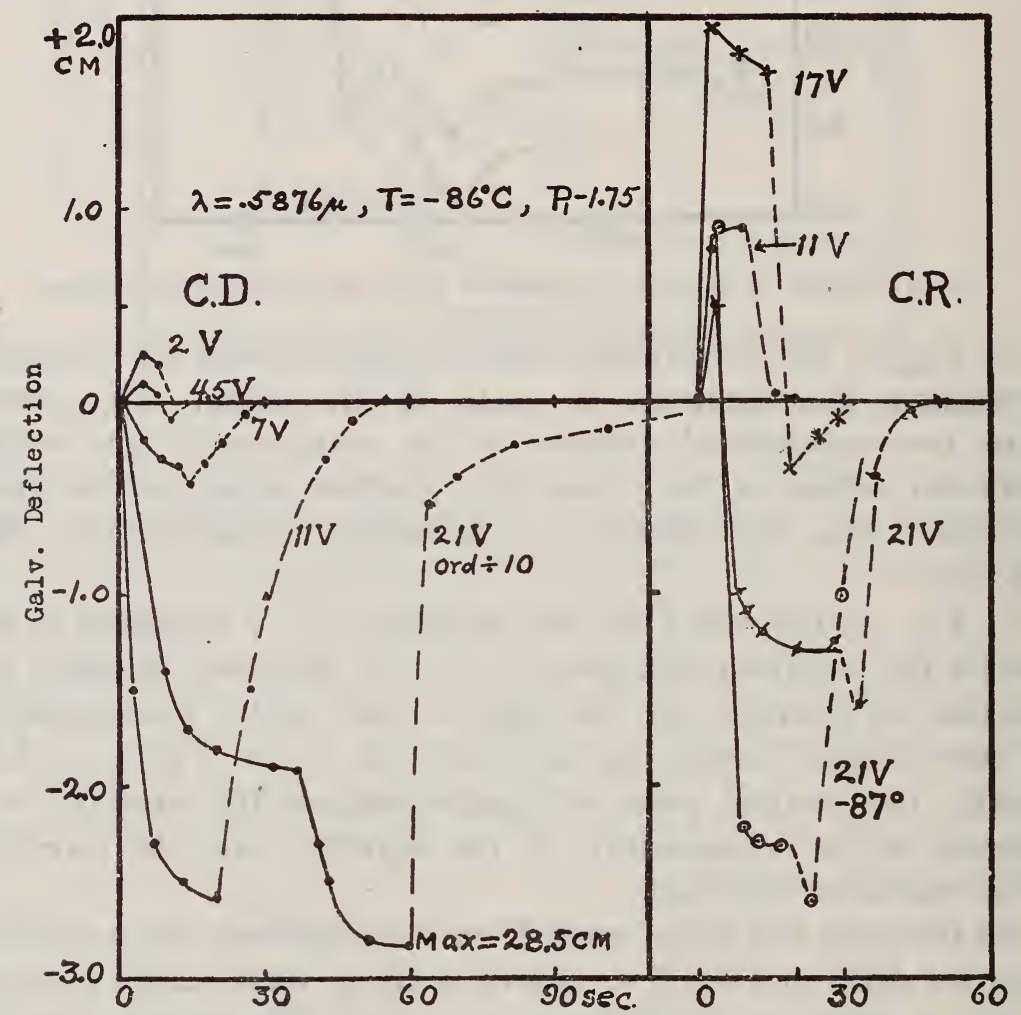

Fig. I8.-Effect of direction and size of applied voltage upon the response-time curves of a photonegative crystal of molybdenite

(a) ISOChromatics-EFFECT OF VOLTAGE AND DiRECTION OF CURRENT.-The purely photonegative reaction of this part of the - crystal was produced on a much lower potential (I I volts, Fig. 18) than was required when the whole length of the sample was exposed to radiation. This is no doubt to be expected from the 
observations given in Fig. 7, which shows a region of weak photopositive reaction.

In Fig. I8, for the current direct, $C . D$., the scale of ordinates for $2 \mathrm{I}$ volts is one-tenth the observed deflections. In this curve the photonegative reaction is quite similar to that previously observed. (See Fig. 8.) However, a secondary reaction seems to occur after the crystal has been exposed to radiation for about 30 seconds. This has been noticed sometimes in photopositive observations, and usually in large photonegative observations, though the phenomenon was not so marked as in the case illustrated in curve $2 \mathrm{IV}, \mathrm{Fig}$. I8. In this case, after an exposure of about 37 seconds, when the deflection had apparently reached equilibrium, the reaction was resumed, adding almost 50 per cent to the first deflection.

When the current was reversed, C. R., Fig. 18, the potentials which were used on $C$. $D$. produced little or no photonegative reaction; for example, $2 \mathrm{IV}, C$. $R$. produced only about onetwentieth the deflection of $2 \mathrm{IV}, C$. D. The effect of temperature upon the negative deflection is very marked, as is shown in curves $2 \mathrm{IV}, C \cdot R$. for -86 and $-87^{\circ} \mathrm{C}$. Here a decrease of about $\mathrm{I}^{\circ} \mathrm{C}$. almost doubled the deflection.

(b) ISOTHERMALS-EFFECT OF DIRECTION OF CURRENT.-It was found that within about I per cent, the dark current for I I volts, $C$. $D$., was the same as that for $\mathrm{I} 7$ volts, $C$. $R$., amounting to $69 \mathrm{~cm}$ at $-84^{\circ} \mathrm{C}$. On 4.5 volts, C. D., the dark current was 25 $\mathrm{cm}$ as compared with $4.9 \mathrm{~cm}$ on $C$. $R$., or a ratio of $\mathrm{r}: 5$.

In Fig. I9 is given the photoelectrical sensitivity of the spot $\mathrm{P}_{1}-\mathrm{I} .75$, Fig. 7 , for the visible spectrum, the temperature being $-84^{\circ} \mathrm{C}$. On $\mathrm{I} 7$ volts, $C$. $R$., the deflection, on shutting off the light, was slightly photonegative at $0.6 \mu$, as indicated by the dotted lines. On the other hand, for i IV, C. D., the deflections on exposure were entirely negative throughout the visible spectrum to $0.657 \mu$ where it was slightly positive, on first exposure, similar to curve $29 \mathrm{~V}$, Fig. 8.

Curve $40 \mathrm{~V}, C . D$, Fig. 19, illustrates the photoelectric reaction in the visible spectrum, the intensity of the radiation stimulus being one-seventh that employed in obtaining the rest of the curves.

It was found that by applying a potential of 22 volts, which produced a large dark current (hence heating of the crystal and unsteadiness of the galvanometer) it was possible to observe a photonegative effect at room temperature, $24^{\circ} \mathrm{C}$. In this curve, 
Fig. 19, the neutral point in the spectrophotoelectric response occurs at wave length $0.677 \mu$ as compared with wave length 0.657 at $-84^{\circ} \mathrm{C}$.

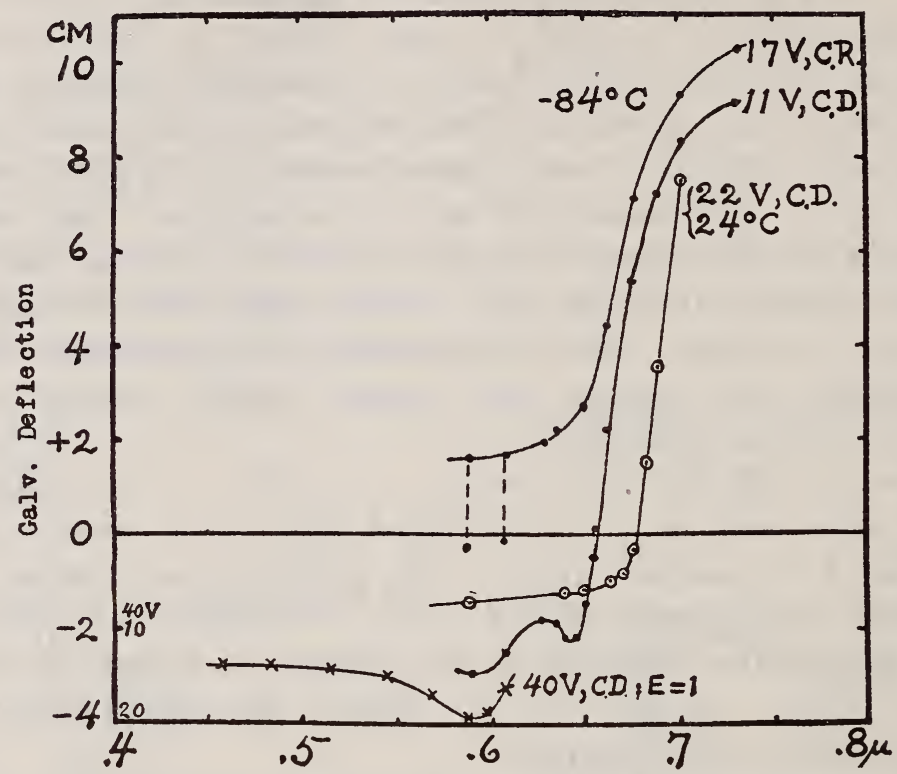

FrG. I9.-Positive and negative photoelectric reactions, using the same dark current through the crystal

The foregoing illustrations show conclusively that, in practically the whole of the visible spectrum, extending to about $0.7 \mu$ in the red, the magnitude and the direction of the current through the crystal has a great effect upon the resulting photoelectric reaction. If it were merely a question of unidirectional conduction, as indicated by the difference in the dark current flowing through the crystal, then, on applying suitable voltages so as to produce equal dark currents in the two directions through the crystal, the spectrophotonegative reaction should also have been the same. This is not true for radiation of wave lengths less than about $0.67 \mu$, where, on $C . R$., a higher voltage than that indicated by the magnitude of the dark current was required to produce a photonegative reaction.

In Fig. 20 it may be noticed that for equal (to about 2 per cent) dark currents in the two directions through the crystal the spectrophotoelectric curves are in excellent agreement in the region of 0.8 to I.I $\mu$. From this it appears that for wave lengths greater than about 0.7 to $0.8 \mu$ the photopositive reaction is not affected by the direction of the current. This was found true also for 
stibnite, Fig. 3, which was examined for the same purpose. In other words, it appears that radiation of wave lengths less than about $0.67 \mu$ can produce an effect similar to polarization, which can not be produced by radiations of long wave length.

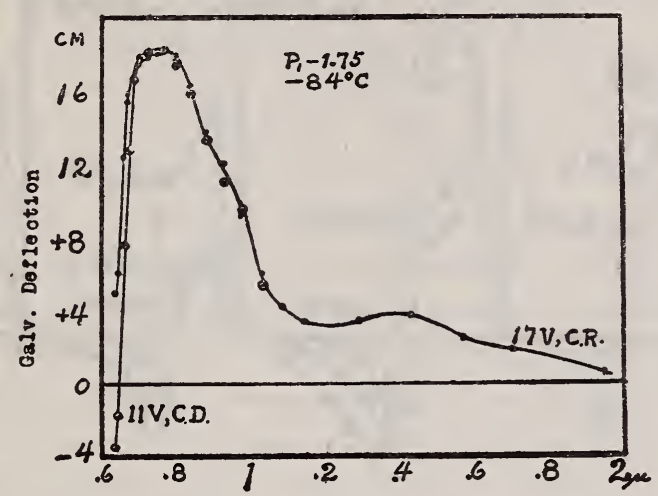

Fig. 20.-Effect of direction, but using the same dark current through the crystal

\section{OBSERVATIONS ON A PHOTONEGATIVE-PHOTOPOSITIVE SPOT}

Referring to Fig. 7 , it may be noticed that about midway between the electrodes, at about $\mathrm{P}_{1}-3$, the photoelectric reaction on 40 volts was first positive followed by an equal negative reaction. It was, therefore, of interest to observe the photoelectric response when both the temperature and radiation stimulus were maintained constant, while the magnitude and the direction of the current were varied. On the highest voltages used the galvanometer was unsteady, owing no doubt to local heating of of the crystal, although not indicated by the thermocouple. For it is to be remembered that the thermocouple was not in contact with the crystal, which is thin and, hence, easily heated above its surroundings. Heating would decrease the intrinsic sensitivity of the crystal.

The observations are illustrated in Fig. 2I. They usually represent the average of several series of observations on a given voltage. Owing to temperature changes the recovery curves, after exposure, do not always coincide, as shown for example, on the curves for I I volts.

It is to be noticed that, in curve $4.5 V, C . D$., the photoelectric action is entirely positive. As the voltage was increased the photopositive reaction on exposure and the photonegative effect on shutting off the light increased to a maximum. The constancy of the reaction after exposure is unusual. Curve $2 \mathrm{I} .5 \mathrm{~V}$ is the 
average of three sets of observations which are in agreement, showing that on about this voltage the positive reaction is the maximum.

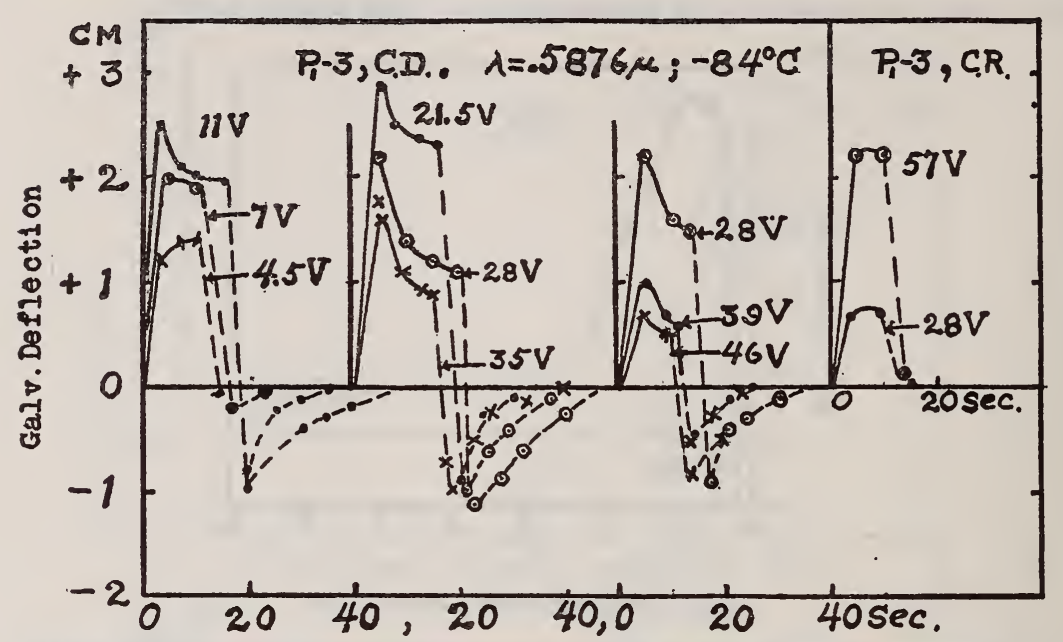

FIG. 2I.-Response-time curves, with variation in voltage and direction of current, of that part of the crystal which showed both the negative and positive photoelectric reaction

The highest voltages that could be used without producing local heating and consequent unsteadiness of the galvanometer failed to produce a pure photonegative deflection. On reversing the current, $C$. $R$., the deflection was positive.

The results of this test show that, in the part of the crystal showing photopositive and photonegative sensitivity, the purely photonegative reaction could not be produced by applying potentials which were considerably higher than those required for producing such a reaction in the region of purely photonegative sensitivity. On the other hand, by applying the proper (much lower) voltage, the reaction in the spot of supposedly purely photonegative sensitivity was similar to that just described.

\section{CONCERNING REACTION TIME}

Various experimenters have recorded observations showing that in selenium and other solid conductors, the maximum photoelectric reaction to visible radiation is attained in a few seconds. On the other hand, for infra-red radiation the reaction requires from $x$ to several minutes to attain equilibrium.

In the previous investigation (loc. cit.) of the photopositive samples of molybdenite it was observed that at 0.6 to $0.7 \mu$ it required 3 to 5 seconds to obtain a maximum galvanometer deflec- 
tion; at $0.75 \mu$ it required a noticably longer time, say, I 5 seconds; at $\mathrm{I} \mu$ it required perhaps $\mathrm{I}$ minute, while at $\mathrm{I} .5$ to $2 \mu$ it required 2 to 3 minutes.

In the foregoing experiments on the photonegative sample of molybdenite, the negative reaction (galvanometer deflection) for radiation of wave lengths 0.5 to $0.6 \mu$ required a minute or more to attain a maximum effect. In the transition region of the spectrum at 0.62 to $0.68 \mu$ this time was a matter of seconds instead of minutes. Beyond $0.9 \mu$ it required $\mathrm{x}$ to 2 minutes to attain equilibrium, depending upon the wave length.

The reaction time appears to be continous, being a minimum at the photoneutral wave length. If a graph be plotted, in which the ordinates represent the time to attain a maximum reaction and the abscissas are the corresponding wave lengths (or perhaps frequencies in order to produce a more symmetrical curve) a Ushaped curve is obtained, the bottom of which occurs at the wave length of transition from the positive to the negative response.

The reversal of the current from $C . V$. to $C$. $R$. did not affect the relative values of the reaction time, especially in the infra-red.

It would be interesting to determine whether all cases of spectrophotoelectric reaction are made up of superposed positive and negative responses, the preponderance of the one or the other depending upon the applied voltage, etc., as observed in this sample of molyodenite. Also, whether the short reaction time in the visible spectrum, especially of photopositive selenium, is merely indicative of the presence of the photonegative reaction, which shortens the time of the reaction but which thus far has escaped detection.

\section{DISCUSSION OF DATA ON MOLYBDENITE}

Under this caption it is relevant to discuss briefly some of the optical and photoelectrical properties of molybdenite and in this manner answer some of the questions that have arisen as to the cause of the observed phenomena; also, other questions that will arise can be anticipated.

First, let us consider the observations, which are sufficiently numerous and varied to answer the question of their authenticity. It has been shown, for the first time, that for the visible spectrum extending to about wave length $0.67 \mu$ the electric response is photopositive or photonegative, depending upon the magnitude of the potential applied and the direction of the current through the crystal. Moreover, a similar spectrophotonegative response, 
with a region of transition at about $0.66 \mu$, observed in stibnite, seems to indicate that this negative spectrophotoelectric property is not unique in molybdenite, but may be a common property of substances which are photoelectrically sensitive. It remains to be determined whether the maximum (or apparently two maxima in molybdenite) of the photonegative response is different for different substances, as is true of the photopositive reaction. This will be of interest in determining whether the photonegative reaction is independent of the medium in which it occurs. As already stated, the close agreement in the wave length of transition from negative to positive reaction, in the case of stibnite and molybdenite, makes a further examination of the subject desirable.

For wave lengths greater than about $0.67 \mu$ the photoelectric response was observed to be photopositive whatever the applied voltage.

The region of transition in the spectrum, in which the action changes from photonegative to photopositive, is very narrow, less than $9 \AA$.

The critical voltage is very small, as may be inferred from the fact that an increase of $\mathrm{I} .3$ volts (additional dry battery) changed a positive-negative galvanometer deflection of $\pm \mathrm{I} \mathrm{cm}$ into a purely negative deflection of -25 to $-30 \mathrm{~cm}$, which is the photonegative response under discussion.

There seem to be two contending forces acting. The one which causes the photopositive response acts quickly and prevails on low voltages. The photonegative action builds up more slowly and is predominant on high voltages. Even while the negative action predominates the positive action seems to be present. As a result of the presence of these two forces, for certain applied voltages, on exposing the molybdenite receiver to radiation of wave lengths less than about $0.67 \mu$, the galvanometer deflection is first positive, then decreases in value, and may even become negative. On shutting off the light stimulus there is a further deflection in the negative direction, after which it returns to the original zero scale reading. For example, as shown in Fig. 8, using radiation of wave length $0.5876 \mu$ as a light stimulus and applying a potential of ro volts, the galvanometer deflection was almost entirely positive; on 20 volts the deflection was partly positive and partly negative; on 29 volts, the positive response was almost eliminated and the negative response prevailed; on 33 volts the galvanometer deflection was entirely negative and 
8 times as large as the observed maximum purely positive deflection for ro volts. In another test, at a slightly lower temperature $\left(-\mathrm{IO}^{\circ} \mathrm{C}\right)$ which raised the critical voltage, changing from 35.6 to 37 volts transformed the positive-negative deflection of $\pm 5 \mathrm{~mm}$ into a negative deflection of $-230 \mathrm{~mm}$.

On lowering the temperature, at about $-20^{\circ} \mathrm{C}$ the recovery from a photonegative reaction is irregular, resulting in overshooting so that momentarily the apparent resistance is less than the normal dark resistance. The curves, illustrated in Fig. II, represent an average of two to four sets of measurements. They are regular in sequence, showing a definite behavior as the temperature is decreased. It is interesting to trace the galvanometer deflection, Fig. I I, from purely positive at $-5^{\circ} \mathrm{C}$ to negativepositive at $-15^{\circ} \mathrm{C}$, to negative-zero at $-18^{\circ} \mathrm{C}$, to negative-partial negative at $-20^{\circ} \mathrm{C}$ and to purely negative at $-40^{\circ} \mathrm{C}$. The positive throws, after exposure, are also regular in their sequence; and they are far greater in magnitude than can be accounted for on the assumption that they are the result of an undamped vibration of the galvanometer coil. For example, at -19 to $-25^{\circ} \mathrm{C}$ the positive deflection, "overshooting," of 4 to $5 \mathrm{~cm}$ on recovery after exposure is as large as the negative response on exposure. The occurrence of the phenomenon can hardly be questioned; though the exact temperature at which this occurs remains undetermined.

The photopositive action is similar to a resistance decrease caused by a rise in temperature of the molybdenite crystal. The photonegative reaction is similar to the building up of a counter emf. In this work an equal energy spectrum was used; that is, the radiation stimuli of different wave lengths were of equal energy value. Hence, if the photopositive response were the result of heating, it should occur in the short wave lengths where the absorptivity of the crystal is the greatest, and the photonegative response should dominate in the long wave lengths where the photoelectric reaction is the greatest. This is just the reverse of what was observed.

These observations can not be explained on the simple and obvious suggestions that first come to one's mind. For example, bolometric measurements indicate that, even if all the radiation were absorbed, the rise in temperature would probably be less than $\frac{1}{50000}{ }^{\circ} \mathrm{C}$, certainly less than $\frac{1}{10000^{\circ}} \mathrm{C}$. Hence, as already mentioned, the positive photoelectric action can not be explained 
on the basis of a resistance decrease as a result of absorption of radiation and a consequent rise in temperature.

Neither can the results be explained on the basis of thermoelectric action. According to Konigsberger ${ }^{15}$ the thermoelectric power of molybdenite against iron is $750 \mathrm{mv}$. This, with the small temperature rise that can occur in the crystal on exposure to radiation, can not produce the relatively large negative effects observed. Furthermore, when the research on the photoelectric properties of molybdenite was begun several years ago, one of the first tests made was for a thermoelectric effect. For this purpose the crystal was connected with a sensitive ironclad Thomson galvanometer and exposed to radiation. No thermoelectric effect was observed, showing that merely warming the crystal by absorption of radiation is not the cause of this photoelectric activity

It does not seem desirable to attempt to explain this photonegative property at this time. If we grant that it is "only a gas effect," a "surface charge," or "electrolytic action," we are confronted with the fact that the reaction is unique in being selective to the frequency (wave length) of the radiation stimulus, and in being photopositive or photonegative, depending upon the magnitude and the direction of the current (the applied voltage) through the crystal. For radiations of wave length greater than about $0.7 \mu$ the reaction was found positive whatever the magnitude or direction of the current.

As already stated, the photonegative reaction has the properties of a counter emf, such as would result from electrolytic conduction. This, in itself, is novel in being produced by thermal radiation of certain frequencies. In other words, we can say that visible radiation can induce electric conduction and a quasi counter emf, while infra-red rays can produce only ionization and electric conduction.

Moreover, as this counter emf builds up and approaches equilibrium, there seems to occur a secondary ionization or reaction (see curve $2 \mathrm{rV}$, Fig. 18) which greatly increases the total photonegative response. A similar irregular building up of the photopositive response was previously observed in thalofide, ${ }^{16}$ but at that time it was thought that this was attributable to changes in contact of the material with the conducting grid. However, it now appears that perhaps this also may have been caused by a secondary reaction.

\footnotetext{
${ }^{15}$ Konigsberger, Jahrb. der Radivaktivität u. Elektronik., 11, p. rox, r9r4; Göttstein, Inaug. Diss. Frei berg in B., I913.

${ }^{16}$ B. S. Scientific Papers, 16, p. 253; $x 920$.
} 
In conclusion, it is of interest to mention the electron theory of the photosensitivity of selenium by Ries. ${ }^{17} \mathrm{He}$ supposes that light liberates slow-moving electrons in the atoms of selenium. These, instead of emerging from the atom, remain within it and add to the number of conducting electrons, thus increasing the conductivity. On this basis one could perhaps extend the theory on the assumption that the short wave lengths liberate electrons of such high velocity that they leave the atom. This would leave positively charged nuclei which, by increasing in number, would build up a counter emf.

These data are in disagreement with the explanation given by Ries who attributed the negative effect in selenium to the presence of moisture and to the passage of the current, and not to the action of the light. The present data show that the photonegative effect is selective to the wave length and is a function of the intensity of the light stimulus. If it were merely a question of current flowing, then the negative effect observed in molybdenite should be greatest for infra-red rays which cause the greatest photoelectric activity. The presence of moisture is not a satisfactory explanation of the photonegative reaction. On this basis one would have to assume that the sample of molybdenite contained a spot which is hydroscopic, and that this moisture could not be removed on evacuation and freezing.

The foregoing observations contradict a number of the conclusions arrived at by Ries (loc. cit.) and by Nicholson, ${ }^{18}$ from which it appears that the whole theoretical groundwork needs revision.

\section{SUMMARY}

In this paper a description is given of a series of new observations on positive and negative spectrophotoelectric reactions in molybdenite, silver sulphide, and stibnite. With these new data are assembled and correlated the few previously observed photonegative reactions in selenium and stibnite.

In view of the numerous variables involved, an attempt was made to determine the effect of each one upon the photoelectrical reaction, while other conditions were kept constant. For example, keeping the temperature constant $\left(-80\right.$ to $-100^{\circ} \mathrm{C}$ was found best) the effect of varying the voltage was observed, and vice versa. Also the effect of the magnitude and direction of

${ }^{17}$ Ries, Phys. Zeit., 12, pp. 480 and 522 ; I9II.

${ }_{18}$ Nicholson, Phys. Rev. (2), 3, p. I; I9I4. 
current through the crystal was observed, as well as the effect of the intensity of the exciting radiation.

It was found that the photopositive action resulting from exposure of these substances to radiation is similar to an increase in their electrical conductivity. The photonegative reaction simulates a counter emf.

These two opposing effects occur simultaneously. The photopositive reaction occurs quickly and prevails on low voltages. The photonegative action usually builds up more slowly and predominates on high voltage. It is selective to the wave length of the radiation stimulus, as well as to the magnitude and direction fo the electric current through the crystal. Temperature also affects the phenomenon and under certain conditions, on exposure of the molybdenite, the photonegative reaction occurs first followed by the photopositive action.

It was found that, for the short wave length region of the spectrum, extending to about $0.67 \mu$, the photoelectric reaction in this sample of molybdenite passes from purely positive on low voltages through intermediate stages to an apparently purely negative reaction on high voltages. Furthermore, this reaction is dependent upon the direction of the current through the crystal. On high voltages a secondary negative reaction appears to be present.

The recovery after exposure is also unusual. When operated on the intermediate voltages, on shutting off the radiation stimulus, the negative effect still further increases, after which the crystal gradually returns to its former dark conductivity. However, on moderately low temperatures, $-20^{\circ} \mathrm{C}$, the recovery from the photonegative reaction is irregular, resulting in overshooting so that momentarily the apparent resistance is lower than the normal dark resistance.

At a given temperature the region of transition in the spectrum, in which the action changes from photonegative to photopositive, is very narrow (less than $9 \AA$ ). It appears to shift slightly toward the short wave lengths with decrease in temperature or increase in intensity of the radiation.

The critical voltage is very small. Under certain temperature conditions an increase of I volt sufficed to change a small positivenegative galvanometer deflection of $\pm \mathrm{I} \mathrm{cm}$ into a pure negative deflection of perhaps $-25 \mathrm{~cm}$. With decrease in temperature the potential must be increased in order to produce a negative reaction. 
For radiations of wave lengths greater than about $0.7 \mu$ the photoelectric reaction in this sample of molybdenite was positive, whatever the magnitude or direction of the current through the crystal. Similar results were obtained on photopositive samples of molybdenite and of stibnite.

The photoelectric reaction in the mineral, acanthite (silver sulphide), differs from that of the negatively reacting sample of molybdenite in that, at room temperature, the partial photonegative reaction is nonselective to wave length. Moreover, for the operable voltages that could be applied, no purely photonegative response could be produced, the reactions being positive-negative similar to those observed in molybdenite on intermediate voltages.

At low temperatures the positive-negative reaction in acanthite disappeared and, on exposure of the crystal to radiation, there was a momentary negative reaction (similar to that observed in molybdenite) followed by a very large positive galvanometer deflection.

The spectrophotonegative effect in stibnite, observed by Elliot, is considered. While no data are at hand concerning the effect of the magnitude and the direction of the current, it is shown that the photonegative reaction for wave lengths 0.5 to $0.67 \mu$, together with the photopositive reaction to radiation of wave lengths greater than $0.67 \mu$, makes it appear that the spectrophotonegative behavior of stibnite is similar to that observed in molybdenite.

The photonegative reaction of selenium to heterochromatic radiation, observed by Ries and by Brown, is similar to that which is observed in molybdenite on the intermediate voltages.

The paper gives data also on unipolar conduction, showing that in spite of the great difference that may occur in the conductivity in the two directions lengthwise through the crystal, this has no effect upon the relative spectrophotoelectric sensitivity curves of substances exhibiting only the photopositive reaction. In three appendixes are given (I) further data on the previously observed frequency relation in the bands of spectrophotoelectric sensitivity of molybdenite, (2) a survey of the general spectrophotoelectrical properties of substances, and (3) a description of experiments on thermal radiophonic signaling.

WASHINGTON, May 8, 1920. 


\section{A P P E N D I XES}

\section{APPENDIX 1.-Further Data on the Spectrophotoelectric-Fre- quency Relation in Molybdenite}

In a previous investigation, ${ }^{19}$ it was observed that the photoelectric sensitivity of molybdenite is confined practically within three spectral bands, the maxima of which are separated by equal frequency intervals.

During the past year, with the assistance of $\mathrm{H}$. Kahler, the investigation was renewed in order to test the validity of this frequency relation, using for the purpose a quartz prism (and apparatus described in the present paper) which gave twice the dispersion obtained with the fluorite prism previously employed. The sample of molybdenite was soldered to copper wire terminals and operated in an evacuated chamber as in previous work. The photoelectric substance, the dry battery, and the d'Arsonval galvanometer were joined in series. The small deflection caused by the small dark current was overcome by rotating the suspension head of the galvanometer, as already described.

Although the dispersion was twice as large as previously employed, the closely situated bands of photoelectric sensitivity at 0.7 to $\mathrm{I} \mu$ (see Figs. I 5 and $\mathrm{I} 6$ ) are not much more sharply defined than previously observed. In investigations of transmission spectra of various substances it was found that usually an increase in the dispersion increased the sharpness of the absorption bands. From this it appears that the photoelectric reaction of a monochromatic light stimulus extends over a wider range of the spectrum than obtains in spectral absorption. The results ${ }^{20}$ obtained with the higher dispersion verify the previous observations indicating that the frequency maxima are separated by equal intervals, which decrease with the temperature. The new data are given in Table $\mathrm{r}$. From both the previous investigation and the present one, it appears that the wave number is of the order $n=40$ (arbitrary units) at $25^{\circ} \mathrm{C}$ and $n=30$ at $-178^{\circ} \mathrm{C}$. As shown in Fig. 16 and Table $\mathrm{r}$, there seem to be additional bands which can be observed under proper temperature conditions. For instance, at $-125^{\circ} \mathrm{C}$ there appear to be four bands in the region of $0.7 \mu$ to $\mathrm{I} . \mathrm{I} \mu$; and the wave number is $\mathrm{I} 6$, which is half the value ordinarily observed.

At this time it is of course impossible to decide whether any significance is to be attached to these data. However, it may be important to point out these relations and record them for future reference. The subject is left with the question unanswered, whether the increased photoelectric sensitivity in the region of $0.7 \mu$ to $I \mu$ is the result of the appearance of new bands, or merely the coalescence and rapid increase in intensity of the old ones.

19 B. S. Scientific Papers, 15, p. I58: I9r9.

${ }^{20}$ Coblentz and Kahler, Phys. Rev. (2). 14, p. 534: I9x9. 
TABLE 1.-Maxima of Photoelectric Sensitivity in Molybdenite and the Wave Number, $n$, or Difference between the Reciprocals of these Wave Lengths
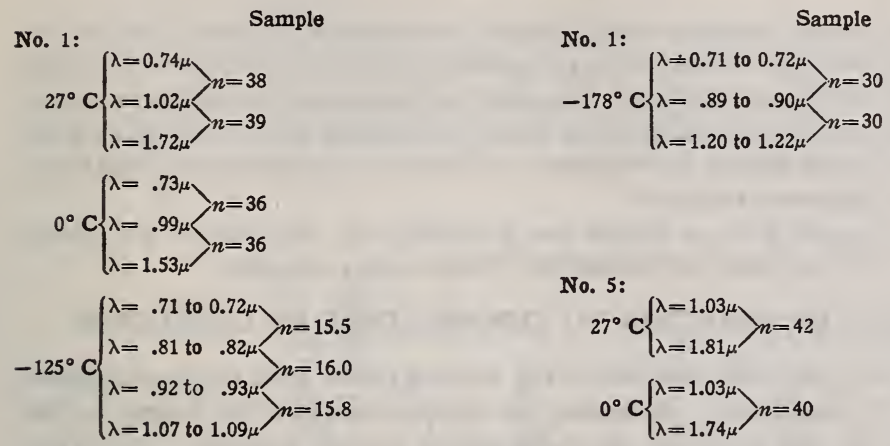

No. 5:

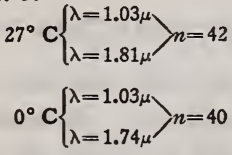

\section{APPENDIX 2.-Some General Characteristics of Spectrophoto- electric Conduction in Solids}

\section{INTRODUCTION}

Although much work has been done on the photoelectrical properties of selenium, until within the past four years no systematic search was made to find solid substances which exhibit photoelectrical properties. ${ }^{21}$ In the meantime a number of spectrophotoelectrical investigations, made principally at this Bureau, on various substances have produced results which can be used to formulate a few general characteristics of spectrophotoelectric sensitivity in solids. ${ }^{22}$

It is found that numerous solid substances which have a low electric conductivity in the dark have a high electric conductivity when exposed to light, selenium being the most widely known example.

This photosensitive property is a function of the temperature of the substance, also of the intensity and of the wave length of the thermal radiation stimulus.

\section{SELECTIVITY OF REACTION TO WAVE LENGTH OF RADIATION STIMULUS}

Using an equal energy stimulus, it is found that, in general, the photoelectric response of substances is fairly uniform throughout the visible spectrum, terminating in a band or bands of high sensitivity in the extreme red ${ }^{23}$ or near infra-red spectrum, at $\mathrm{I} .2 \mu$. Molybdenite is unique in having three bands of spectrophotoelectric sensitivity, which extends to $2 \mu$.

\section{SELECTIVITY OF REACTION TIME}

It is well known that the photoelectric response of selenium lags considerably more for infra-red rays than for visual rays. Molybdenite and Case's thalofide cell are much quicker than selenium in their photoelectric response (change in electric conductivity) when exposed to radiation, irrespective of wave length.

In the visible spectrum the photoelectric reaction attains equilibrium within a few seconds after exposure. On the other hand, it requires from one to several minutes exposure to infra-red rays in order to obtain the maximum photoelectric action. Decreasing the temperature appears to shorten the time required for attaining the maximum photoelectric response for all wave lengths ${ }^{24}$.

${ }^{21}$ Case, Phys. Rev., (2), 9, p. 305; April, r9r7. Coblentz, Proc. Phil. Soc. Wash., Feb., 19r 7 ; Jour. Wash. Acad. Sci., 7, p. 525, 19r7; and B. S. Bulletin, 14, p. 59r, I9r8.

22 Jour. Optical Soc. of America, 4, No. 5; 1920.

${ }^{23}$ Cuprous oxide appears to have its maximum sensitivity in the ultra-violet; Pfund, Phys. Rev., 7 , p. $289 ; 1916$

${ }^{24}$ B. S. Scientific Papers, 15, p. I32; rgrg. 


\section{SELECTIVITY OF REACTION TO INTENSITY OF RADIATION} STIMULUS

Using an equal energy spectrum and different intensities it is found that the resulting change in electrical conductivity or reaction is selective with respect to the wave length of the radiation stimulus. The effect of increasing the radiation stimulus appears to produce a greater response in the long wave lengths than in the short wave lengths, with a resultant shift of the maximum of the spectral photoelectric sensitivity curve toward the long wave lengths ${ }^{25}$.

There does not appear to be a simple law governing the variation in the photoelectric response with variation in intensity of the radiation stimulus.

\section{SELECTIVITY OF REACTION TO TEMPERATURE OF SUBSTANCE}

The temperature of the substance has a very marked effect upon the spectrophotoelectric reaction of a substance. Reducing the temperature to a low degree by immersion in liquid air, the substance is practically an electric insulator. Nevertheless, on exposure to radiation of certain wave lengths the electric conductivity is greatly increased.

A typical example is that of stibnite, illustrated in Figs. 2 and 3 . These curves show that as the temperature decreases the radiations of short wave lengths produce a greater change in electric conductivity than do the long wave lengths. As a result, the maximum of the sensitivity curve is shifted toward the short wave lengths. Furthermore, the maxima are generally very much sharper at low temperatures, as found by Elliot ${ }^{26}$ for selenium and by the writer ${ }^{27}$ for silver sulphide.

\section{SUMMARY}

In the foregoing pages attention is called to the fact that numerous solid substances which have a low electric conductivity in the dark have a high electric conductivity when exposed to light.

A study of some of these substances shows that their photoelectric reactions have the following characteristics:

I. The photoelectric response to an equal energy stimulus is fairly uniform throughout the visible spectrum, terminating in a band or bands of high photoelectric sensitivity in the extreme red or near infra-red spectrum.

2. The time required to attain equilibrum of the photoelectric reaction is selective to wave length. For visible radiation the photoelectric response is complete in a few seconds, whereas it requires an exposure of one to several minutes to infra-red rays in order to induce the maximum photoelectric response.

3. The effect of increasing the intensity of the radiation stimulus is to produce a greater increase of the photoelectric response in the long wave lengths than in the short wave lengths, with a resultant shift of the maximum of the spectral photoelectric sensitivity curve toward the long wave lengths.

4. Decreasing the temperature of the substance greatly increases the intrinsic photoelectric sensitivity throughout the whole spectrum and shifts the maximum sensitivity toward the short wave lenghts.

\section{APPENDIX 3.--Thermal Radiophonic Signaling Devices ${ }^{28}$}

During the military activities some attention was given to the application of thermal radiodynamic devices for the transmission of intelligence and for the detection ${ }^{29}$

${ }^{25}$ See data on silver sulphide, B. S. Scientific Papers, 15, p. 208; 1919

${ }^{26}$ Elliot, Phys. Rev. (2), 5, p. 59; 1915.

B. S. Scientific Papers, 15, p. 242; rgrg.

${ }_{28}$ U. S. patent No. $1,345,586$, July 6,1920 ; dedicated to the public.

$\approx$ Phys. Rev. (2), 15, p. 340; 1920. 
of invisible objects by the radiations they emit. In concluding this subject some of these data are given here, with the thought that they may find a useful application in scientific investigations.

The subject of signaling has been discussed in books written by Rühmer and by Miessner. They mention the use of selenium, which at that time (Igr3) was practically the only photoelectrically sensitive substance known. Even in the most recent apparatus devisad by Rankine ${ }^{30}$ for the transmission of speech by light, selenium is used as a receiver.
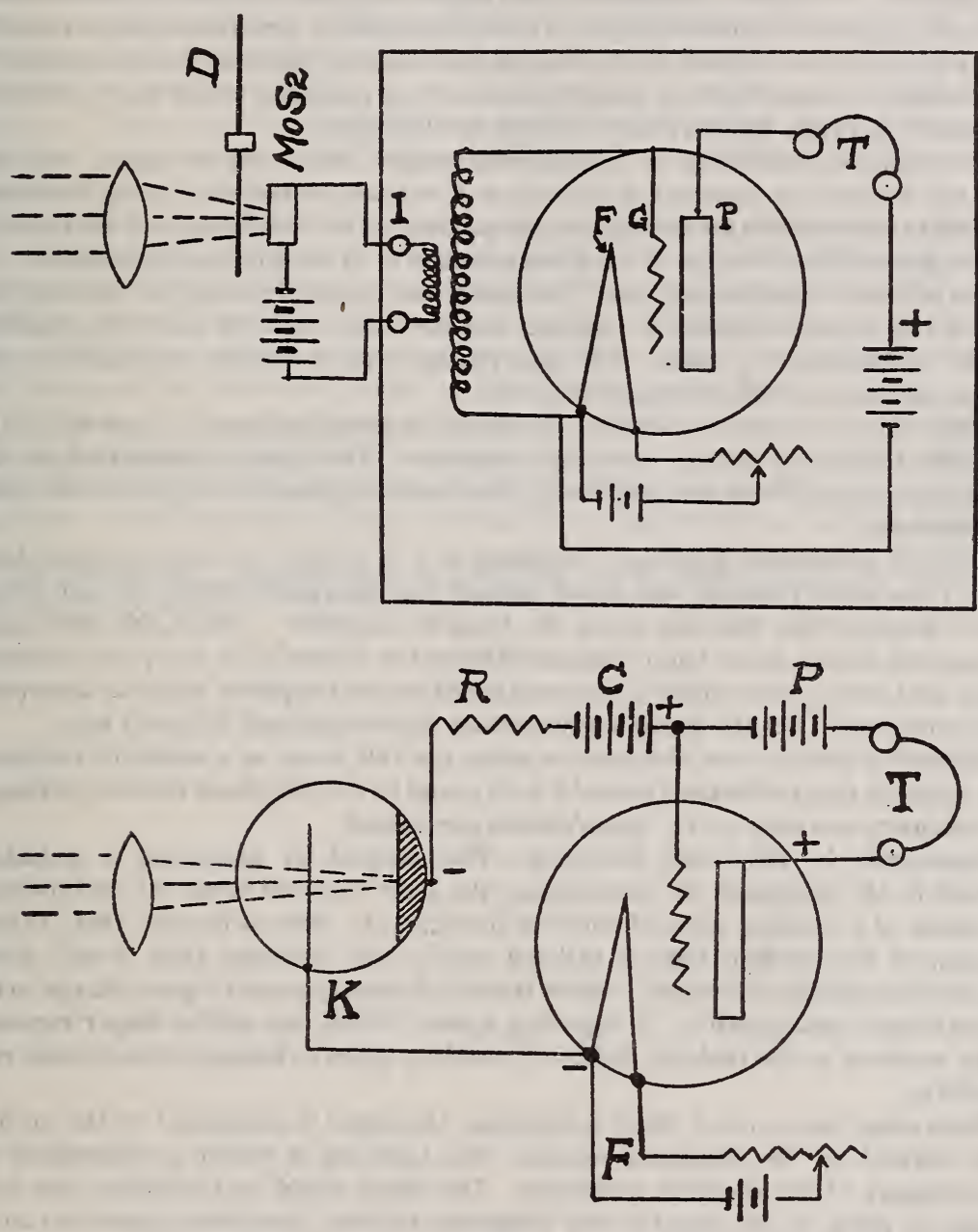

Fig. 22.-Electrical connections of radiophonic apparatus

The high photoelectric sensitivity and the quickness of action of some samples of molybdenite (and of stibnite) make it far superior to selenium as a radiophonic signaling device, in which a pulsating electric current is produced by interrupting the incident radiations by means of a rotating sectored disk.

The radiophonic signaling apparatus used in the sensitivity tests consisted of a crystal of molybdenite and a battery of dry cells, giving 40 to 60 volts, connected

${ }^{30}$ Rankine, Proc. Phys. Soc., London, 31, p. 242; I9r8. 
directly to the input terminals, I, of a 3 -stage amplifier, as shown in the upper part of Fig. 22. A concave silver-on-glass mirror, $16 \mathrm{~cm}$ in diameter, $50 \mathrm{~cm}$ focal length, was used to concentrate the radiations upon the molybdenite receiver. For a field outfit the mirror, sectored disk, $\mathrm{D}$ (the motor operated on a 6 volt battery), and molybdenite receiver were mounted upon a camera tripod.

Tests were made also with a receiver consisting simply of a thin strip of gold (or platinum) smoked on one side and attached to suitable electrodes. ${ }^{31}$ In the latter arrangement the gold-leaf receiver and storage battery were connected to the lowvoltage side of a suitable transformer, the high-voltage side of which was connected with the input side of the amplifier. It was interesting to find that the heat capacity of the gold leaf was so small that, although the radiation stimulus was interrupted at the frequency of audibility, a pulsating current was produced which was of sufficient amplitude to excite the telephone receiver to audibility.

The radiation sensitivity of molybdenite sample No. I was compared with the gold-leaf receiver by exposing it directly to a standard or radiation, using minimum audibility as a criterion for making the comparison. The results showed that molybdenite sample No. I was 150 to 200 times as sensitive as the gold-leaf radipohone.

FIELD TESTS.-For making tests ${ }^{32}$ the most convenient signaling stations were the roof of this Bureau's electrical building and the clock tower of the U. S. Soldiers' Home-a distance of 3 miles. The intervening space was partly occupied by city houses and streets with attendant dust, etc.

A test of the field outfit was made, the source of radiation being a (250 watt) $300 \mathrm{cp}$ tungsten lamp in a $28 \mathrm{~cm}$ searchlight reflector. The signals transmitted by the absorption screens were loud and easily perceived in spite of a high wind and other disturbances.

Using an automobile headlight, consisting of a $20 \mathrm{cp}$ (say, 20 watt) tungsten lamp in a $I_{5} \mathrm{~cm}$ metal reflector, the signal through the absorption screen was not always heard, showing that this was about the limit of audibility. When this field outfit was sighted upon a street lamp (tungsten filament in a clear bulb, $80 \mathrm{cp}$ ) at a distance of one-half mile, a clear audible note was heard in the telephone when no absorption glass intervened; but the signal was uncertain when using only infra-red rays,

Interesting results were obtained on using the full moon as a source of radiation. The infra-red lunar radiations caused a loud sound in the telephone receiver, although the intensity was only $3 \times 10^{-7}$ gram calorie per second.

COMPARISON OF Signaling METHODS.-The method of producing a pulsating current in the telephone by interrupting the light incident upon the molybdenite by means of a rotating sectored wheel is inefficient in view of the fact that (I) only one-half of the incident light is utilized and (2) the exposure time is only about one five-hundredth of a second, which is not sufficient to permit a great change in the photoelectric conductivity. A signaling system which can utilize longer exposure of the receiver to the incident light will obtain a greater change in the electric conductivity.

When using the sectored wheel radiophone, the signal is recognized by the musical note emitted by the telephone receiver, the loudness of which is determined by the intensity of the incident radiations. The signal could be recognized also by a change in pitch of the sound in the telephone receiver, provided apparatus can be devised to function by changing the pitch of the sound. This change in pitch was frequently observed in the amplifier used in these experiments, but it was found to be inefficient (insensitive) and not reproducible. However, such a method is feasible, in view of the fact that an audion bulb, evacuated to a few millimeters gas pressure, can be made to transmit a pulsating current. A change in current in the grid, or

31 B. S. Bulletin, 14, pp. 534 and 597 ; r9r8.

32 Made with assistance of $H$. Kahler and M. B. Long. 
input circuit, causes a change in frequency of the pulsating current, and hence a change in pitch of the sound produced in the telephone receiver. The time of exposure of the signal light can be made quite long so as to utilize the full change in conductivity of the crystal receiver.

The change-in-pitch method of signaling seemed so attractive that an attempt was niade to obtain a test of its efficiency as compared with the sectored disk radiophone, using in both devices the molybdenite for the receiver of the thermal radiations which were used in transmitting the signal. The result of this test showed that, owing to a high resistance, which was in series with the single receiver of molybdenite, but which did not function photoelectrically when exposed to light, the method of signaling by change in pitch was not so sensitive as the rotating sectored disk radiophone. Using several molybdenite receivers joined in series so as to obtain the required high resistance when exposed to light, the sensitivity of this device was improved.

A photoelectric cell of the gas-ionic type, for example, the potassium hydride photoelectric cell, K, Fig. 22, is well adapted for use with this change-in-pitch method of signaling. The high resistance is used as ballast to the photoelectric cell. ${ }^{33}$ This combination was found to be the most sensitive of the radiophonic type of receivers yet tested. The applied voltage can be adjusted so that the telephone receiver emits a sound only when the photoelectric cell is exposed to light.

Very instructive experiments can be performed with such a device. For example, the rate of charge and discharge can be adjusted so that the sound in the telephone is a series of clicks which increase in rapidity with increase in intensity of the exciting light. This, no doubt, in time will find useful applications in research work.

${ }^{33}$ This arrangement of apparatus differs from Lrangmuir's, U. S. Patent, $1,273,627$, July 23, I918, and I,282,439, Oct. 22, I9I8. 




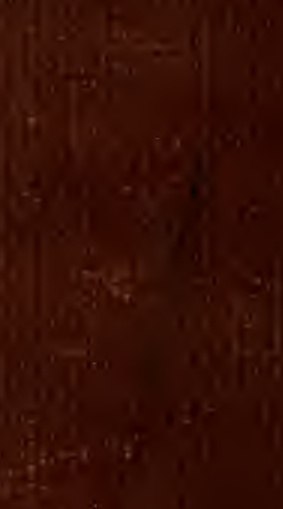

